\title{
¿Characteristics and Dynamics of Density Fronts over the Inner to Midshelf under Weak Wind Conditions
}

\author{
Xiaodong Wu, ${ }^{\mathrm{a}}$ Falk Feddersen, ${ }^{\mathrm{a}}$ And SARAh N. Giddings ${ }^{\mathrm{a}}$ \\ ${ }^{a}$ Scripps Institution of Oceanography, University of California, San Diego, La Jolla, California
}

(Manuscript received 17 July 2020, in final form 2 December 2020)

\begin{abstract}
Here, we explore the kinematics and dynamics of coastal density fronts (within $10 \mathrm{~km}$ from shore and $<30$-m depth), identified using an edge detection algorithm, in a realistic high-resolution model of the San Diego Bight with relatively weak winds and small freshwater input. The density fronts have lengths spanning $4-10 \mathrm{~km}$ and surface density gradients spanning 2-20 $\times 10^{-4} \mathrm{~kg} \mathrm{~m}^{-4}$. Cross-shore-oriented fronts are more likely with northward subtidal flow and are $1 / 3$ as numerous as alongshore-oriented fronts, which are more likely with onshore surface baroclinic diurnal flow. Using a subset of the cross-shore fronts, decomposed into cross-front mean and perturbation components, an ensemble front is created. The ensemble cross-front mean flow is largely geostrophic in the cross- and alongfront directions. The ensemble cross-shore front extends several kilometers from shore, with a distinct linear front axis and downwelling (upwelling) on the dense (light) side of the front, convergent perturbation cross-front flow within the upper $5 \mathrm{~m}$, strengthening the ensemble front. Vertical mixing of momentum is weak, counter to the turbulent thermal wind mechanism. The ensemble cross-shore front resembles a gravity current and is generated by a convergent strain field acting on the large-scale density field. The ensemble front is bounded by the shoreline and is alongfront geostrophic and cross-front ageostrophic. This contrasts with the cross-front geostrophic and alongfront ageostrophic balances of classic deformation frontogenesis, but is consistent with semigeostrophic coastal circulation.
\end{abstract}

KEYWORDS: Ageostrophic circulations; Coastal flows; Frontogenesis/frontolysis; Fronts; Momentum; Ocean models

\section{Introduction}

The sea surface density field contains rich variability over submesoscale $O(0.1-10) \mathrm{km}$ length scales (e.g., McWilliams 2016) that often manifest as density fronts and filaments. Previous studies have shown that submesoscale fronts and filaments in the open ocean (hundreds of kilometers from shore) can affect the transport of biogeochemical tracers and contaminants (e.g., Franks 1992; Nagai et al. 2015; Mahadevan 2016; Lévy et al. 2018). Submesoscale density fronts are ubiquitous on continental shelves in high-resolution coastal models (e.g., Romero et al. 2016; Dauhajre et al. 2017, 2019), observed within $10 \mathrm{~km}$ from shore (e.g., Ohlmann et al. 2017; Connolly and Kirincich 2019), and detected in satellite sea surface temperature (SST) images (e.g., Castelao et al. 2006; Kahru et al. 2012). Dye and SST observations reveal frontal variability within $1 \mathrm{~km}$ from shore (Hally-Rosendahl et al. 2015; Grimes et al. 2020). Fronts alter Lagrangian transport pathways and water mass structure over the continental shelf (e.g., Banas et al. 2009; Rao et al. 2011). Here, we focus on the dynamics of submesoscale fronts in the shallow coastal ocean $(<10 \mathrm{~km}$ from shore and $<30$-m water depth). In coastal regions at $O(0.1-$ 10) $\mathrm{km}$ length scales, studies have largely focused on fronts associated with inlet and river plumes (e.g., O'Donnell 2010; Chant 2011; Horner-Devine et al. 2015; Feddersen et al. 2016) and upwelling (e.g., Brink 1987; Austin and Barth 2002; Austin and

¿ Denotes content that is immediately available upon publication as open access.
Lentz 2002). Instead, we focus on coastal fronts in a region of weak winds and no significant freshwater flows, a poorly studied part of the coastal submesoscale frontal parameter space.

A companion paper of this work (Wu et al. 2020, hereinafter W20) investigated the processes transporting shoreline released dye representing wastewater off the San Diego (United States)/Tijuana (Mexico) coast in the San Diego Bight (see Fig. 1) using a high-resolution realistic wave-current coupled model. On the mid- to outer shelf boundary (smoothed 25-m isobath, $\approx 5 \mathrm{~km}$ from shore), wind-driven Ekman transport and submesoscale flows both played an important role in offshore dye transport during a three month analysis period. The submesoscale flows were elevated for stronger root-mean-square (rms) surface alongshore density gradients at length scales $<$ $15 \mathrm{~km}$, which were enhanced by the large scale (over $\approx 15 \mathrm{~km}$ alongshelf) convergent northward alongshore flow, suggesting cross-shore-oriented fronts. In high-resolution numerical models, density gradients are preferentially perpendicular to bathymetric contours in depths $<50 \mathrm{~m}$ (Romero et al. 2013; Dauhajre et al. 2017), suggesting alongshore-oriented fronts and filaments. In general, the kinematics (i.e., occurrence likelihood, orientations, lengths, and density gradient magnitude) of coastal (within $10 \mathrm{~km}$ of shore) density fronts in regions with little freshwater input are poorly understood.

Mechanisms for both forced and unforced frontogenesis often have been examined with a frontogenesis tendency equation for the material derivative of the horizontal density gradient magnitude squared (e.g., Hoskins 1982; O’Donnell 2010),

$$
\frac{D\left(\left|\nabla_{H} \rho\right|^{2}\right)}{D t}=F,
$$




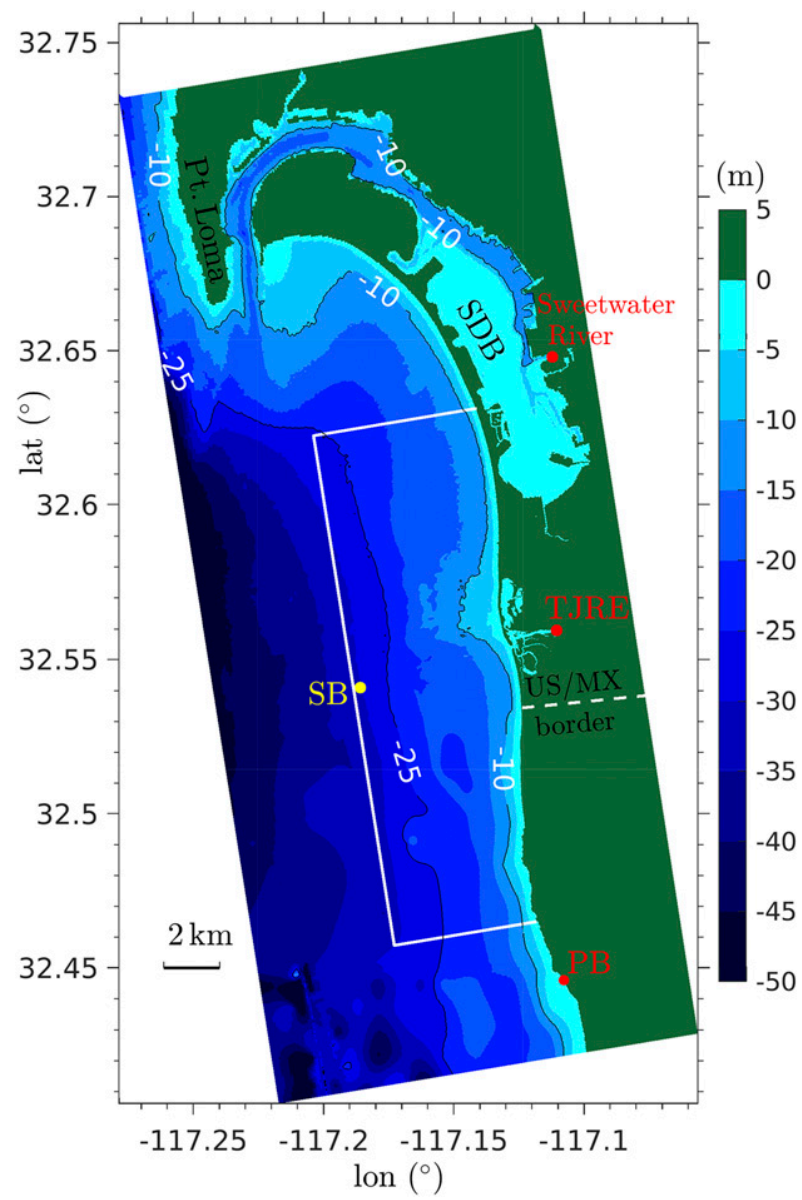

FIG. 1. LV4 grid bathymetry (color shading) and the front study region (white line) to which mean front locations are restricted. Red dots denote the freshwater sources Punta Bandera (PB), Tijuana River Estuary (TJRE), and Sweetwater River. The yellow dot denotes the South Bay Ocean Outfall (SB) mooring site in 30-m depth. San Diego Bay (SDB), Point Loma, and the U.S.Mexico border are also labeled.

where $\nabla_{H}$ denotes the horizontal gradient and $F$ comprises the enhancing (positive $F$, frontogenetic) or weakening (negative $F$, frontolytic) driving terms. Many coastal fronts are forced by freshwater input or wind-driven upwelling (Austin and Lentz 2002; Horner-Devine et al. 2015). In shallow water, forcing by tides and bathymetry can generate differential mixing/advection and induce fronts (e.g., Simpson et al. 1978; Huzzey and Brubaker 1988). In the open ocean, unforced mechanisms for generating frontogensis have been proposed including deformation frontogenesis (DF; Hoskins and Bretherton 1972) and turbulent thermal wind balance (TTW; McWilliams et al. 2015).

The DF mechanism involves a large-scale geostrophic, nondivergent strain field whose cross-front convergence enhances the density gradient and accelerates an alongfront jet, which via Coriolis forcing induces an ageostrophic cross-front flow $v_{a}$ (Hoskins and Bretherton 1972; Hoskins et al. 1978). The induced $v_{a}$ and the associated downwelling and upwelling form an ageostrophic secondary circulation (ASC) tilting the isopycnals toward the horizontal (e.g., Bleck et al. 1988; Spall 1995; Thomas et al. 2008). TTW refers to a balance among vertical mixing, Coriolis and pressure gradient forcing (McWilliams et al. 2015), where the ageostrophic Coriolis forcing is balanced by vertical mixing (Garrett and Loder 1981; Thompson 2000; Gula et al. 2014; Wenegrat and McPhaden 2016). Cross-front varying vertical mixing of momentum [i.e., $\partial_{z}\left(A_{v} \partial_{z} u\right)$, where $A_{v}$ is the vertical eddy viscosity and $u$ is the alongfront velocity] can induce a cross-front ageostrophic convergence $\partial v_{a} / \partial y \neq 0$, enhancing the density gradient and forming a TTW ASC (McWilliams 2017). In numerical models in the Gulf of Mexico, the density gradient of TTW generated fronts and filaments can strengthen rapidly on hourly time scales consistent with an asymptotic model assuming weak near-surface stratification (Barkan et al. 2019). The TTW mechanism was invoked to explain the strengthening of coastal density filaments and fronts during winter and spring in a highresolution numerical model (Dauhajre et al. 2017). However, to what extent the DF and TTW mechanisms are generally applicable to generation of density fronts in coastal regions within $10 \mathrm{~km}$ from shore is unclear. Stratification and wind forcing in coastal regions vary dramatically. The spatial variability of horizontal density gradient varies seasonally in the California Current System (CCS; Kahru et al. 2012; Mauzole et al. 2020) and in the Gulf Stream (Callies et al. 2015). The shoreline limits the onshore extent of fronts, the shore normal velocity vanishes at the shoreline, and shallow coastal depths constrain frontal vertical circulation. The shoreline also constrains shelf circulation to largely a geostrophic (ageostrophic) balance in the cross-shore (alongshore) direction (e.g., Allen 1980; Lentz et al. 1999).

Here, we focus on the kinematics and dynamics of coastal density fronts (within $10 \mathrm{~km}$ from shore and $<30-\mathrm{m}$ depth) using a high-resolution numerical model of the San Diego Bight (W20). A field study in this region noted the enhancement of a dye alongshore front driven by the internal tide (Grimes et al. 2020). In this region, winds are relatively weak and freshwater input is small, placing focus on unforced (e.g., DF and TTW) frontogenesis mechanisms. An edge detection method is used to isolate individual density fronts. We address three main questions. What are the kinematic properties (i.e., orientation, length and density gradient) of these coastal fronts? For cross-shoreoriented fronts, what does a typical front look like? What are the processes responsible for the frontogenesis and can they be classified in the context of open ocean unforced frontogenesis mechanisms? The model configuration, front detection procedure, and front kinematic parameters are given in section 2. Front kinematic properties and variability are analyzed in section 3 . An ensemble mean cross-shore-oriented front is created to quantify frontal circulation in section 4. Frontogenesis mechanisms are diagnosed through frontogenesis tendency and a momentum balance analysis in sections 5 and 6, respectively. Front dynamics in the context of DF and TTW mechanisms are discussed in section 7. A summary is provided in section 8 .

\section{Model configuration and front detection}

\section{a. Model setup}

Shelf and surfzone circulation is simulated using the Coupled Ocean-Atmosphere-Wave-Sediment-Transport (COAWST) 
model system (Warner et al. 2010; Kumar et al. 2012). A full description of the model setup is found in W20. Here only the information essential to this work is provided. The model consists of three one-way nested parent runs (from LV1 to LV2 and then LV3) spanning from the California Current System to the south Southern California Bight, and one downscaled highresolution child run (LV4) resolving the outer to inner shelf and surfzone in the southern San Diego Bight (Fig. 1). LV4 incorporates surface waves by coupling the Regional Ocean Modeling System (ROMS; Shchepetkin and McWilliams 2005) with the Simulating Waves Nearshore model (SWAN; Booij et al. 1999). NOAA/NAM surface fluxes (wind stress, heat, and precipitation) are applied. Vertical mixing (eddy viscosity and diffusivity) is derived from a $k-\epsilon$ submodel (e.g., Umlauf and Burchard 2003) with Kantha and Clayson (1994) stability functions. In all simulations, a third-order upwind advection scheme is used for momentum. The horizontal eddy viscosity and diffusivity are constant at $0.5 \mathrm{~m}^{2} \mathrm{~s}^{-1}$ over all the model runs. For the LV4 grid, this horizontal eddy viscosity and diffusivity have little effect on submesoscale variability (W20).

The LV4 grid $\left(15 \times 36 \mathrm{~km}^{2}\right)$ spans from Punta Bandera (PB), Mexico, to Point Loma, United States, encompassing the Tijuana River Estuary (TJRE) and the San Diego Bay (SDB) (Fig. 1). The shoreline is relatively straight, except for curvature around SDB and a broad 15-m depth shoal offshore of the TJRE mouth. The horizontal grid resolution transitions from $100 \mathrm{~m}$ along the three open boundaries to $8 \mathrm{~m}$ approaching the TJRE mouth, resulting in a regional mean resolution $\approx 30 \mathrm{~m}$. The vertical stretched grid has $15 s$ levels with enhanced resolution near the surface and bottom. The number of vertical levels is limited to prevent thin vertical layers in very shallow $(<1 \mathrm{~m})$ depths. As we are focused on surface density fronts, we provide context of vertical grid resolution. In 30-m depth, the average vertical resolution is $\Delta z=0.8 \mathrm{~m}$ for $z>-5 \mathrm{~m}$ and for $-10<z<-5$, the average vertical resolution is $\Delta z=2 \mathrm{~m}$. The initial and boundary conditions, nested from the parent LV3 solution, include both barotropic and baroclinic tides. Barotropic tides are prescribed on the outmost LV1 grid, allowing for the generation of baroclinic tides within all model domains (e.g., Kumar et al. 2015; Suanda et al. 2017; Kumar et al. 2019). LV4 receives realistic freshwater discharge from PB, TJRE, and the Sweetwater River within SDB. TJRE discharge occurs following intermittent rainfall events. At PB, untreated wastewater outflows are represented with a constant freshwater discharge $\left(Q_{r}=1.53 \mathrm{~m}^{3} \mathrm{~s}^{-1}\right.$; see W20 for more details). The simulation is conducted from July to October 2015 using XSEDE resources (Towns et al. 2014), and solutions are saved at 1-h intervals.

\section{b. Regional oceanographic conditions}

Following W20, model results are analyzed over the summer to fall transition (22 July-18 October 2015, denoted analysis period). The barotropic mixed tides have an amplitude around $1 \mathrm{~m}$ (Fig. 2a). NAM winds are mostly southeastward directed and have a low $\left(\left|\mathbf{U}_{w}\right|<5 \mathrm{~m} \mathrm{~s}^{-1}\right)$ to moderate $\left(5-8 \mathrm{~m} \mathrm{~s}^{-1}\right)$ speed (Fig. 2b). The shelf stratification is represented by the top-tobottom buoyancy frequency $N^{2}=-\left(g / \rho_{0}\right) \Delta \rho / \Delta z$ at a central location denoted SB (30-m depth, see Fig. 1 for location),
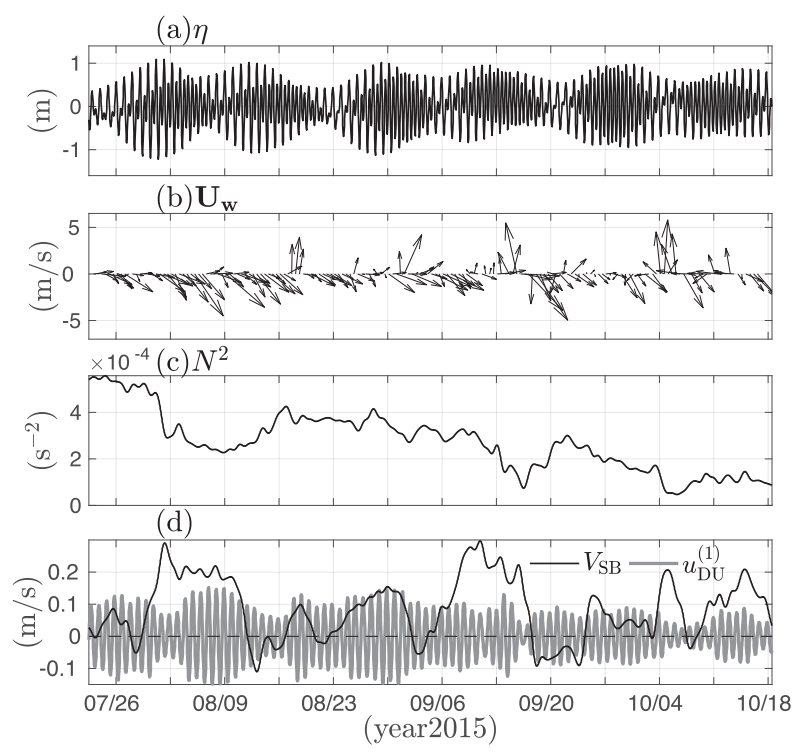

FIG. 2. Time series of (a) sea surface level $\eta$ at SB, (b) 12-hourly wind vectors at $\mathrm{SB}$, (c) subtidal top-to-bottom buoyancy frequency $N^{2}$ at SB, and (d) subtidal depth-averaged alongshore velocity at SB $V_{\mathrm{SB}}$ and surface cross-shore first-mode diurnal velocity $u_{\mathrm{DU}}^{(1)}$ averaged along a smoothed $25-\mathrm{m}$ isobath.

where $g$ is gravity and the background density $\rho_{0}=$ $1025 \mathrm{~kg} \mathrm{~m}^{-3}$. The subtidal (low-pass filtered with a $33-\mathrm{h}$ cutoff) $N^{2}$ decreases overall from a relatively strong $5 \times$ $10^{-4} \mathrm{~s}^{-2}$ during summer to $1 \times 10^{-4} \mathrm{~s}^{-2}$ during fall (Fig. 2c), typical for summer to fall stratification in this region of Southern California (e.g., Palacios et al. 2004). Within the LV4 grid, the time-mean surface density has a weak northsouth gradient reaching a midshelf (25-m isobath) magnitude of $6 \times 10^{-6} \mathrm{~kg} \mathrm{~m}^{-4}$ with lighter water to the north (W20). This is due to the regional differences in upwelling between Southern California and Baja California (e.g., Huyer 1983), which is also seen in the parent LV3 grid (W20). The SDB has negligible freshwater input during this time period (W20); however, the warm water of the SDB serves as a weak buoyancy source, which may slightly augment this already present north-south regional density gradient. The subtidal depth-averaged alongshore flow at $\mathrm{SB}, V_{\mathrm{SB}}$, varies between -0.1 and $0.3 \mathrm{~m} \mathrm{~s}^{-1}$ and is mostly positive (northward directed, Fig. 2d). Diurnal (DU, from $33^{-1}$ to $16^{-1} \mathrm{cph}$ ) baroclinic velocities are significant in this region. Following W20, a complex EOF derived cross-shore (cross-isobath) surface diurnal velocity $u_{\mathrm{DU}}^{(1)}(t)$ is estimated on a smoothed $25-\mathrm{m}$ depth contour. The diurnal velocity $u_{\mathrm{DU}}^{(1)}$ has a modulating amplitude around $0.1 \mathrm{~m} \mathrm{~s}^{-1}$ (Fig. 2d) that weakens with the reduced $N^{2}$ later in the analysis period.

\section{c. Surface density front identification}

Surface density fronts frequently occur during the analysis period, as shown in the two examples (Fig. 3). In the first example, the $\approx 6$-km-long surface density front is steeply angled relative to the cross-shore direction and is mostly onshore of the $25 \mathrm{~m}$ isobath (Fig. 3a). This front was compressed in the 
(a) 7-Aug 18:00UTC
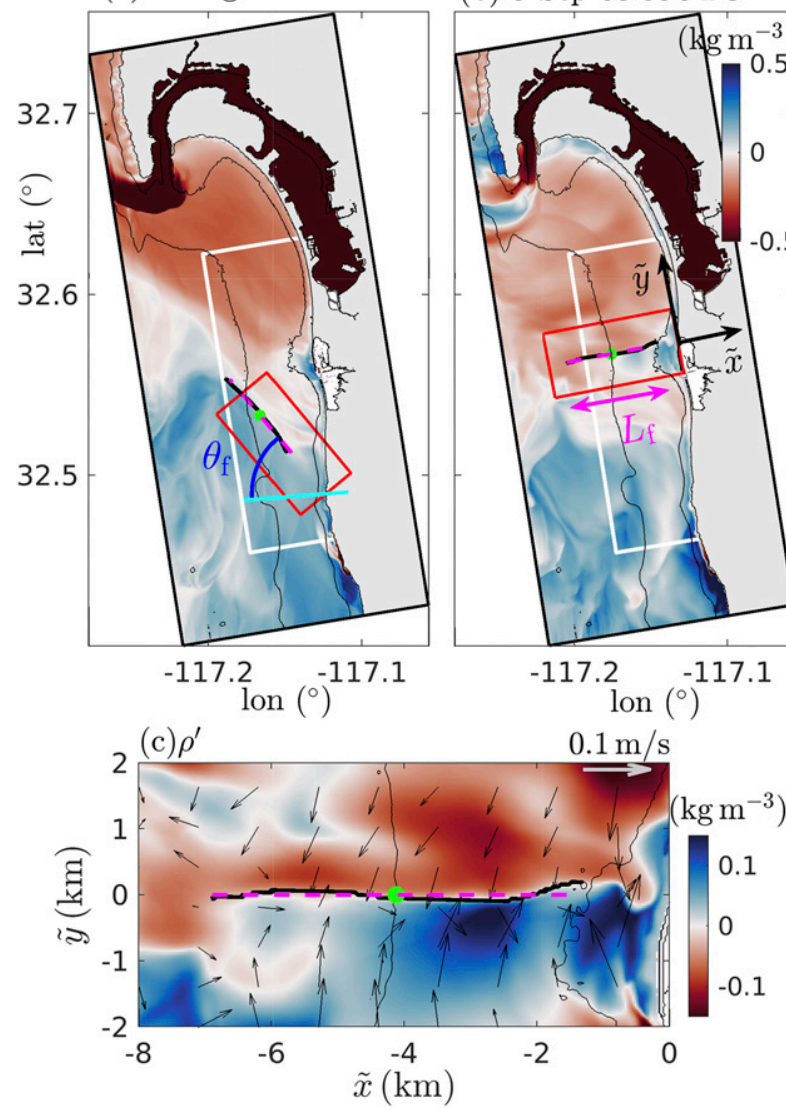

FIG. 3. Surface density perturbation (after removing the spatial mean within the front study region, color shading), the detected front (bold black line), and the frontal control volume (red rectangle) of (a) an inclined and (b) a cross-shore oriented front. (c) Zoom-in of the cross-shore front density perturbation $\rho^{\prime}$ (after removing the cross-front mean) and the surface current perturbation (after removing the cross-front mean, vectors) within the control volume in (b). In (a), the cyan line denotes the shoreline normal direction. In each panel, the green dot shows the mean front location, the dashed magenta line is the front axis, and the thin black contour denotes isobaths $h=[10,25] \mathrm{m}$.

alongshore direction by the convergent alongshore flow (as described in W20, Fig. 3 therein). In the second example, the surface density front is much more aligned in the cross-shore direction with a length of $\approx 5 \mathrm{~km}$ (Fig. $3 \mathrm{~b}$ ).

Both example density fronts are primarily located within the front study region (see white box in Fig. 1), a bounded region $\left(5.5 \times 18.5 \mathrm{~km}^{2}\right)$ that extends from the shoreline to the $\approx 30-\mathrm{m}$ isobath and spans the surfzone through midshelf. The region's southern and northern boundaries are $5 \mathrm{~km}$ away from the grid's southern open boundary and $7 \mathrm{~km}$ from the SDB mouth, respectively. Surface density fronts primarily contained within this study region are the focus of this work.

Modeled surface density fronts are identified by applying the Canny edge detection algorithm (Canny 1986) to the surface density. This algorithm has been successfully applied to front detection in SST satellite images (e.g., Castelao et al. 2006;
Jones et al. 2012). The algorithm first interpolates the surface density onto an equally spaced horizontal grid with $\Delta=40-\mathrm{m}$ resolution, coarser than the grid mean resolution $(\approx 30 \mathrm{~m})$ to preserve data quality. Then, density is smoothed using a $2 \mathrm{D}$ Gaussian filter with a $\sqrt{2} \Delta$ standard deviation (std). The horizontal density gradient $\nabla_{H} \rho$ is computed by convoluting the smoothed density with the spatial derivative of the 2D Gaussian filter (Canny 1986). The algorithm finds grid points with $\left|\nabla_{H} \rho\right|$ larger than a threshold $\left|\nabla_{H} \rho\right|_{c}$ (described below), which are labeled as a front. Thereafter, the algorithm tracks the grid points that are connected to the front with a $\left|\nabla_{H} \rho\right|$ larger than a smaller threshold $c\left|\nabla_{H} \rho\right|_{c} \quad[c=0.4$, following Castelao et al. (2006)], adding these grid points to the front. This approach results in more contiguous fronts and reduces multiple patchy fronts. The algorithm is applied to each hour of model outputs over the analysis period. Note that, some fronts detected at consecutive time steps are the same front advected to a new location. For simplicity, frontal evolution is not considered here and each identified front at each time step is considered separately.

For our analysis, we focus on fronts that are relatively straight, are longer than $4 \mathrm{~km}$, and are not strongly affected by open boundaries, SDB outflow, or the surfzone. Thus, we apply the following criteria to reject fronts identified by the edge detection algorithm. First, the mean front location (i.e., center of mass of the front, green dot in Figs. 3a and 3b) must be located within the front study region. Second, the offshore end of the front must be at least $1.5 \mathrm{~km}$ from the shoreline, to ensure that surfzone processes are not dominating the front. Third, the front is fit to an ellipse. To ensure relatively straight fronts, we require that the ratio of the ellipse minor to major axes $\gamma<$ 0.15 . Fourth, we require that the front length is $>4 \mathrm{~km}$. Both example fronts (Fig. 3) pass the criteria as their mean location is within the front study region, their lengths are $>4 \mathrm{~km}$, and their $\gamma=0.06$ and $\gamma=0.04$.

Applying the edge detection algorithm and four criteria, the total number of detected fronts $N_{f}$ over the analysis period $\left(2112 \mathrm{~h}\right.$ ) is a function of the threshold $\left|\nabla_{H} \rho\right|_{c}$ (Fig. 4). As $\left|\nabla_{H} \rho\right|_{c}$ increases from 0.2 to $12.3 \times 10^{-4} \mathrm{~kg} \mathrm{~m}^{-4}$, the total count decreases from $N_{f}=6742$ to $N_{f}=371$ (Fig. 4), and the mean hourly front count decreases from 3.2 to 0.17 . For the following analysis, we choose the $\left|\nabla_{H} \rho\right|_{c}$ threshold as the inflection of the curve (triangle in Fig. $4,\left|\nabla_{H} \rho\right|_{c}=2.9 \times 10^{-4} \mathrm{~kg} \mathrm{~m}^{-4}$ ). This choice requires fronts to have a relatively strong density gradient while it allows sufficient fronts $\left(N_{f}=2948\right)$ for statistical analyses. The lower cutoff $c\left|\nabla_{H} \rho\right|_{c}=1.2 \times 10^{-4} \mathrm{~kg} \mathrm{~m}^{-4}$ is comparable to the upper end of the smoothed $25-\mathrm{m}$ isobath $\mathrm{rms}$ alongshore density gradient $1.5 \times 10^{-4} \mathrm{~kg} \mathrm{~m}^{-4}$ (W20).

For the $N_{f}=2948$ selected fronts, kinematic front parameters are defined. First, a front axis is defined as the least squares fit line to the front (see magenta dashed line in Figs. 3a and 3b). A front orientation angle $\theta_{f}\left(\theta_{f} \in\left[-90^{\circ}, 90^{\circ}\right]\right)$ is the angle between the mean shoreline normal direction $\left(5^{\circ}\right.$ clockwise from the grid cross-shore orientation, see cyan line in Fig. 3a) and the front axis (see Fig. 3a). For fronts that tilt northward offshore, $\theta_{f}<0^{\circ}$ (Fig. 3a). The front length $L_{f}$ is defined as the length of the front projected onto the front axis (Fig. 3b). The alongfront mean surface density gradient $\left|\nabla_{H} \rho\right|_{f}$ is calculated by averaging the surface $\left|\nabla_{H} \rho\right|$ along the bending front. Note 


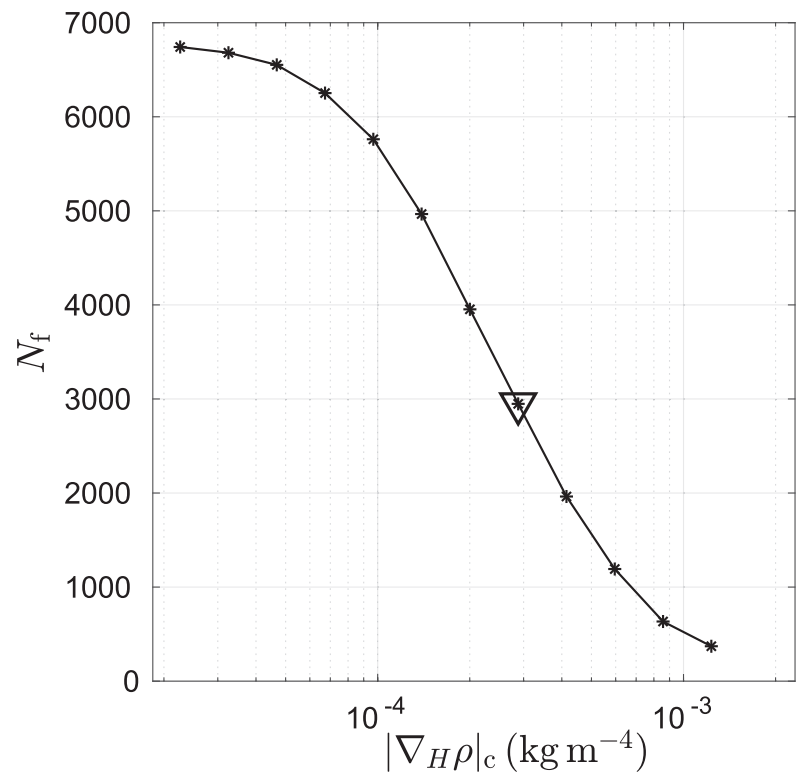

FIG. 4. Total front count $N_{f}$ versus the cutoff surface density gradient $\left|\nabla_{H} \rho\right|_{c}$. The triangle highlights the inflection point of the curve that corresponds to $\left|\nabla_{H} \rho\right|_{c}=2.9 \times 10^{-4} \mathrm{~kg} \mathrm{~m}^{-4}$.

that $\left|\nabla_{H} \rho\right|_{f}$ magnitude must be $\geq c\left|\nabla_{H} \rho\right|_{c}$. For reference, the first example front (Fig. 3a) has $\theta_{f}=-54^{\circ}, L_{f}=5.9 \mathrm{~km}$, and $\left|\nabla_{H} \rho\right|_{f}=3.0 \times 10^{-4} \mathrm{~kg} \mathrm{~m}^{-4}$ and the second example front (Fig. 3b) has $\theta_{f}=6^{\circ}, L_{f}=5.5 \mathrm{~km}$, and $\left|\nabla_{H} \rho\right|_{f}=5.6 \times$ $10^{-4} \mathrm{~kg} \mathrm{~m}^{-4}$.

\section{Kinematic frontal properties}

\section{a. Kinematic front parameter statistics}

Here, a statistical analysis on the kinematic front parameters $\left(\theta_{f}, L_{f},\left|\nabla_{H} \rho\right|_{f}\right.$, and front mean location) is performed on the
$N_{f}=2948$ selected fronts. The front orientation angle $\theta_{f}$ histogram has a U-shaped distribution (Fig. 5a) with maxima near $\pm 90^{\circ}$ (fronts aligned with the shoreline) and a minimum near $\theta_{f}=0^{\circ}$ (fronts shore-normal oriented). The prevalence of alongshore-oriented fronts is generally consistent with modeled inner to midshelf density gradients preferentially aligned across isobath (Romero et al. 2013; Dauhajre et al. 2017). Based on the $\theta_{f}$ distribution, fronts are categorized into alongshore oriented, cross-shore oriented, and inclined fronts. Alongshore fronts are defined as having a near-shoreline (within $20^{\circ}$ ) orientation, that is $\theta_{f} \in\left[-90^{\circ},-70^{\circ}\right]$ or $\theta_{f} \in\left[70^{\circ}\right.$, $90^{\circ}$ ] (dark gray shading in Fig. 5a). Cross-shore fronts are defined as having an orientation $\theta_{f} \in\left[-50^{\circ}, 50^{\circ}\right]$ (light gray shading in Fig. 5a, an example in Fig. 3b). Separating the alongshore and cross-shore fronts are inclined fronts, defined as having an orientation $\theta_{f} \in\left[-70^{\circ},-50^{\circ}\right]$ or $\theta_{f} \in\left[50^{\circ}, 70^{\circ}\right]$ (see example in Fig. 3a). Overall, the alongshore-oriented, inclined, and cross-shore-oriented fronts account for $55 \%, 27 \%$, and $18 \%$ of the total fronts, respectively. Thus, the cross-shore fronts are about $1 / 3$ as numerous as alongshore fronts. The cross-shore fronts have the widest angular range as the crossshore shear of the alongshore flow can tilt cross-shore fronts. Cross-shore fronts tilting northward offshore $\left(\theta_{f}<0^{\circ}\right)$ are more likely than those tiling southward offshore $\left(\theta_{f}>0^{\circ}\right.$, Fig. 5a), as the alongshore flow is mostly northward directed (see $V_{\mathrm{SB}}$ in Fig. 2d).

For all fronts, the front length $L_{f}$ histogram is quasiexponential with $L_{f}=4 \mathrm{~km}$ most likely and the $L_{f} \geq 16 \mathrm{~km}$ likelihood reduced by factor of 50 (Fig. $5 \mathrm{~b}$ ). The $L_{f}$ histogram for alongshore and cross-shore fronts separately is also quasiexponential. Alongshore fronts are generally longer than cross-shore fronts. Alongshore fronts have mean ( \pm std) $L_{f}=$ $7.8( \pm 3.4) \mathrm{km}$, while cross-shore fronts have mean $( \pm \mathrm{std}) L_{f}=$ $5.8( \pm 1.8) \mathrm{km}$. Longer cross-shore fronts $\left(L_{f}>8 \mathrm{~km}\right)$ are more likely for more negative $\theta_{f} \approx-50^{\circ}$. The grid offshore boundary is $\approx 10 \mathrm{~km}$ from the shoreline and the grid alongshore
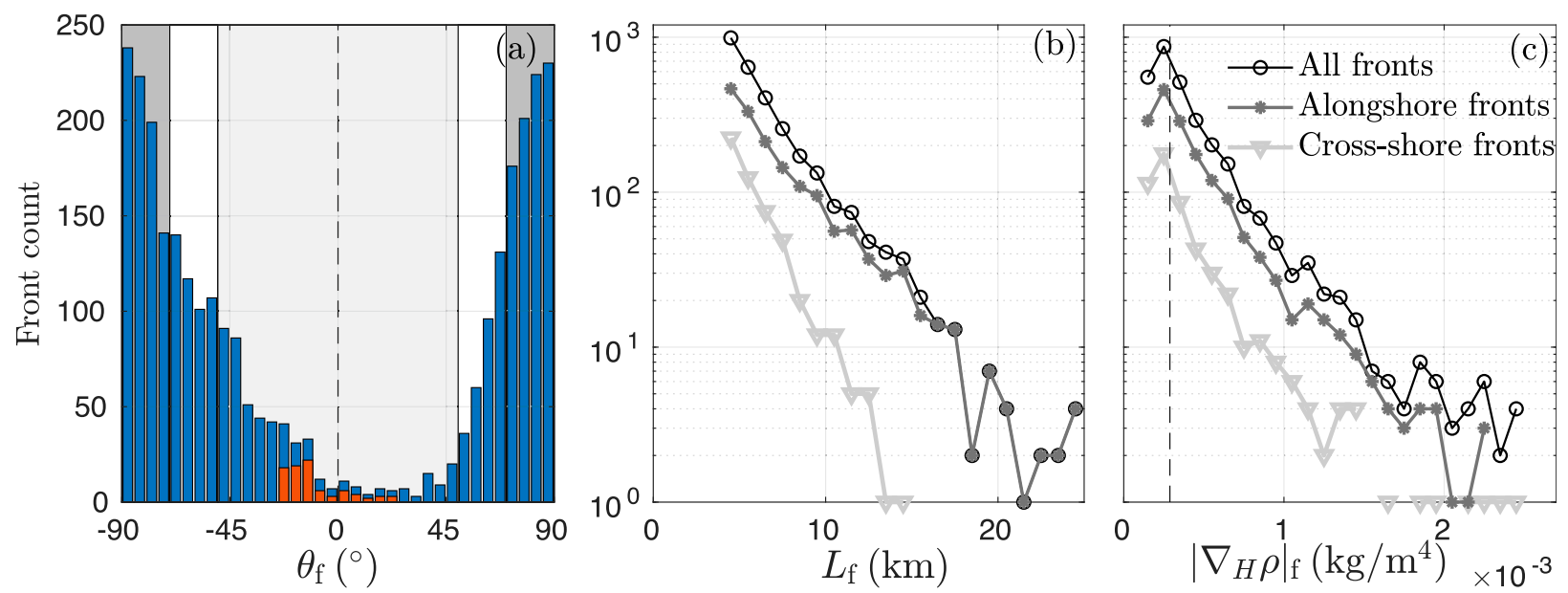

FIG. 5. (a) The front orientation $\theta_{f}$ histogram (blue bars), and histogram (on logarithmic scale) of (b) the front length $L_{f}$ and (c) the alongfront averaged density gradient $\left|\nabla_{H} \rho\right|_{f}$ for all the fronts (circle). The fronts are categorized into alongshore [dark gray shading in (a), star marker in (b) and (c)], inclined, and cross-shore [light gray shading in (a), triangle marker in (b) and (c)]. In (a), red histogram indicates the 86 cross-shore fronts used to create the ensemble mean front (section 4). The dashed line in (c) denotes $\left|\nabla_{H} \rho\right|_{c}$. 
(a1) Cross-shore fronts

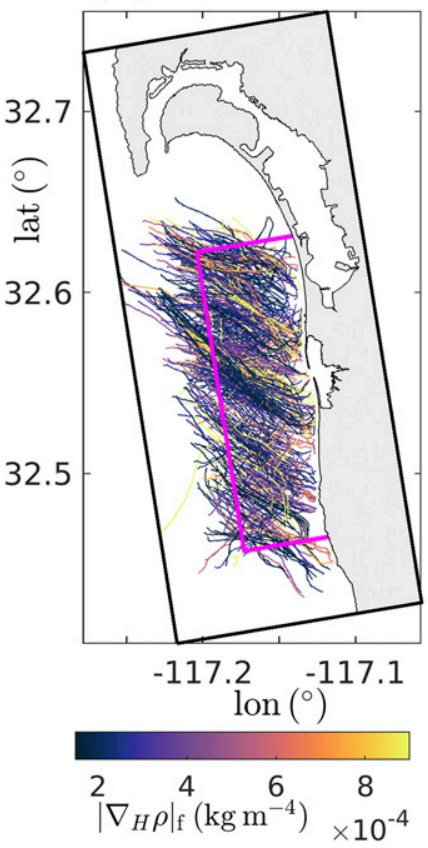

(a2) $N_{f}=528$

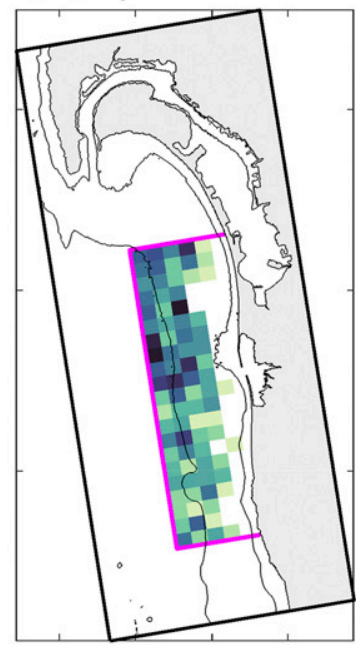

$-117.2-117.1$ $\operatorname{lon}\left({ }^{\circ}\right)$

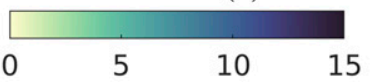

(b1) Alongshore fronts

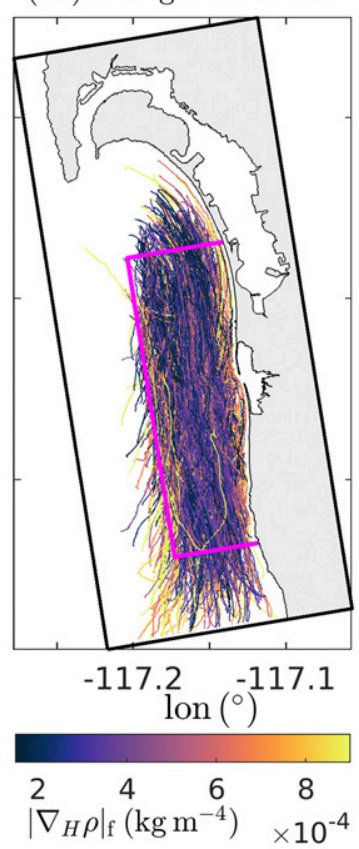

(b2) $N_{f}=1632$

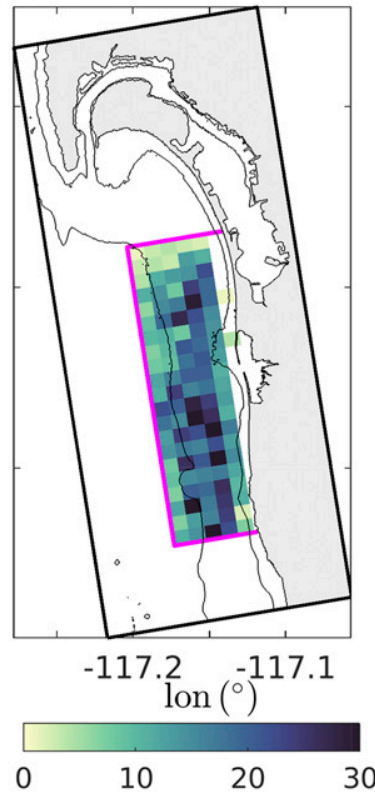

FIG. 6. (a1),(b1) Front spatial distribution and (a2),(b2) the binned mean front location for all (a) cross-shore and (b) alongshore fronts. In (a1) and (b1), the front color represents the alongfront averaged density gradient $\left|\nabla_{H} \rho\right|_{f}$. Black contours in (a2) and (b2) denote the 10and $25-\mathrm{m}$ isobaths.

dimension is $36 \mathrm{~km}$, possibly limiting cross-shore and alongshore front $L_{f}$.

For all fronts, the alongfront averaged density gradient $\left|\nabla_{H} \rho\right|_{f}$ histogram is skewed with maxima at $\left|\nabla_{H} \rho\right|_{c}$ and an exponential decrease for larger $\left|\nabla_{H} \rho\right|_{f}$ (Fig. 5c). The $\left|\nabla_{H} \rho\right|_{f}$ can vary by a factor of 10 , from 2 to $20 \times 10^{-4} \mathrm{~kg} \mathrm{~m}^{-4}$. Although the alongshore fronts are more numerous, both alongshore and cross-shore fronts have similar mean $\left|\nabla_{H} \rho\right|_{f}$ with values of $4.2 \times 10^{-4} \mathrm{~kg} \mathrm{~m}^{-4}$ and $3.9 \times 10^{-4} \mathrm{~kg} \mathrm{~m}^{-4}$, respectively. For both cross-shore and alongshore fronts, no relationship between $\left|\nabla_{H} \rho\right|_{f}$ and $\theta_{f}$ is evident (not shown). Two-thirds of the alongshore fronts have a positive mean cross-front density gradient (denser water onshore). For the cross-shore fronts, $90 \%$ have negative mean density gradient (lighter water to the north). The $\left|\nabla_{H} \rho\right|_{f}$ of crossshore fronts are $\approx 2$ times larger than the rms alongshore density gradient along a smoothed $25 \mathrm{~m}$ depth contour (W20).

Next, the spatial distribution of the cross- and alongshore fronts is examined for preferred frontal position within the front study region. For example, the intermittent TJRE discharge and the TJRE shoal may promote local frontogenesis. The $N_{f}=528$ cross-shore fronts are present throughout the front study region, mostly tilting northward offshore (Fig. 6a1). The range of $L_{f}$ and $\nabla_{H} \rho$ for the cross-shore fronts is also evident. The cross-shore front mean location (center of mass) has $\approx 2 / 3$ of fronts located northward of the TJRE mouth, and $\approx 1 / 3$ located south of the TJRE mouth (Fig. 6a2). The alongshore fronts also are present throughout the front study region (Fig. 6b1). Alongshore front mean cross-shore location is twice as likely to occur at the midpoint of the front study region rather than its offshore end (Fig. 6b2). Alongshore front mean location is somewhat more likely found south of the TJRE mouth, relative to the north.

\section{b. Cross-shore and alongshore front occurrence frequency}

The differences in front kinematic parameters $\left(\theta_{f}, L_{f}\right.$, center of mass, Figs. 5 and 6) suggest that different processes are responsible for generating the cross-shore and alongshore fronts. Here, we examine the factors affecting the temporal variability of frontal occurrences and the mean $\left|\nabla_{H} \rho\right|_{f}$ for both cross-shore and alongshore fronts. The hourly front count $n_{f}(t)$ is defined as the number of identified fronts for a particular hour. For crossshore fronts, the hourly front count $n_{f}$ varies between 0 and 5 , with a time mean $( \pm$ std) of $0.25( \pm 0.60)$ (Fig. $7 b)$. Cross-shore front hourly $n_{f}$ are elevated during four time periods (i.e., 29 August, 29-30 August, 8-16 September, and 12-16 October), coincident with the periods of positive (northward) $V_{\mathrm{SB}}$ (Fig. 7a). The hourly $n_{f}$ of the alongshore fronts ranges between 0 and 10 , with a time mean $( \pm$ std) of $0.75( \pm 1.2)$ (Fig. 7c). The alongshore front $n_{f}$ is not related to $V_{\mathrm{SB}}$. Alongshore fronts are detected for 84 out of 88 days of the analysis period (i.e., $95 \%$ of the period), and the $n_{f}$ has consistent diurnal variability.

To further investigate the relationship between frontal temporal variability and flow conditions, the cross-shore and alongshore hourly $n_{f}$ are bin averaged using $V_{\mathrm{SB}}$ and the surface diurnal velocity $u_{\mathrm{DU}}^{(1)}$ (section $2 \mathrm{~b}$ ) in Fig. 8 . For cross-shore fronts, the bin-mean hourly $n_{f}<0.1$ for negative (southward) $V_{\mathrm{SB}}$, and increases with positive (northward) $V_{\mathrm{SB}}$ to $n_{f} \approx 0.7$ for $V_{\mathrm{SB}} \approx 0.25 \mathrm{~m} \mathrm{~s}^{-1}$ (Fig. 8a). This is consistent with the elevated 

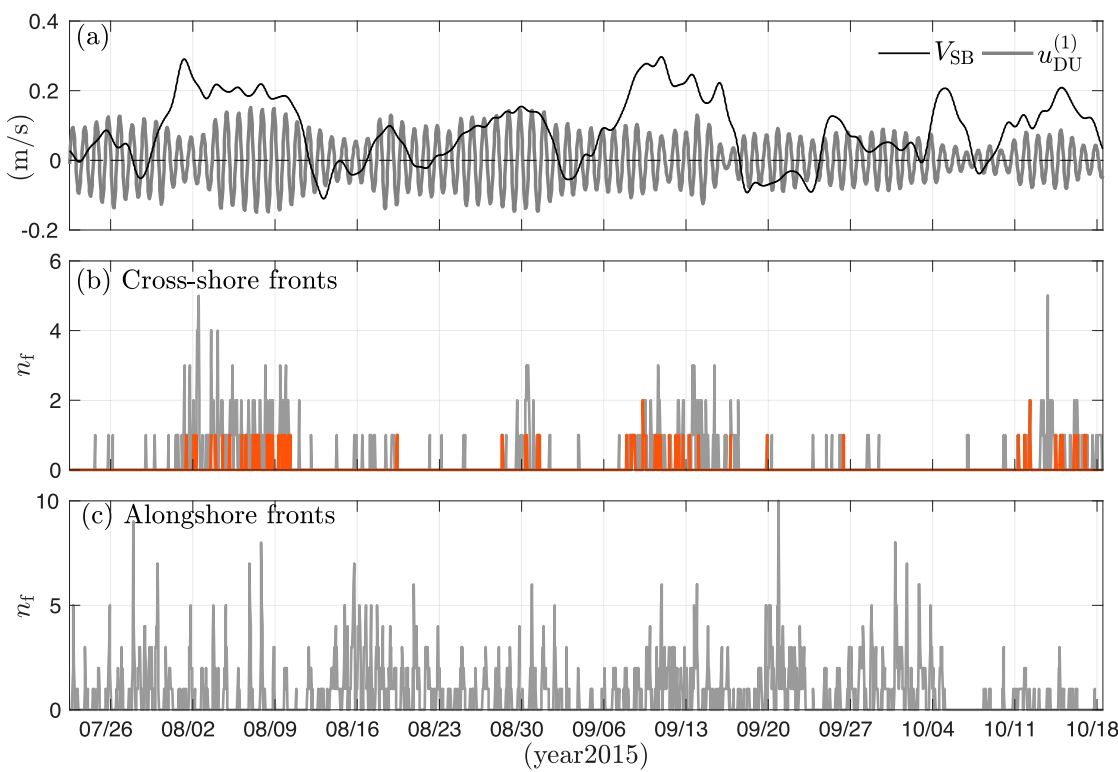

FIG. 7. Time series of (a) subtidal alongshore velocity $V_{\mathrm{SB}}$ (black) and the diurnal-band surface baroclinic cross-shore velocity $u_{\mathrm{DU}}^{(1)}$ (gray) as in Fig. 2d, (b) hourly front count $n_{f}$ for cross-shore fronts (gray line), and (c) the alongshore fronts. In (b) the red line denotes the 86 fronts used to create ensemble mean front (section 4).

rms alongshore density gradient along the smoothed $25 \mathrm{~m}$ isobath for stronger northward $V_{\mathrm{SB}}$ (W20). The bin-mean front density gradient $\left|\nabla_{H} \rho\right|_{f}$ is slightly elevated for $V_{\mathrm{SB}}>0.1 \mathrm{~m} \mathrm{~s}^{-1}$ compared with that when $V_{\mathrm{SB}}<0.1 \mathrm{~m} \mathrm{~s}^{-1}$. The binned mean cross-shore front $n_{f}$ has no relationship to the SDB outflow velocity at zero to $6 \mathrm{~h}$ time lag (not shown). This indicates that SDB-sourced buoyancy is not generating the cross-shore fronts. The binned mean cross-shore front $n_{f}$ also has no relationship to the alongshore (grid aligned) subtidal wind stress nor the surface baroclinic diurnal velocity $u_{\mathrm{DU}}^{(1)}$ (not shown). Overall, this indicates that northward alongshore flow on 2-7-day time scales affects the generation of cross-shore fronts.

For the alongshore fronts, the binned-mean hourly $n_{f}$ is small $(\leq 0.5)$ for $u_{\mathrm{DU}}^{(1)}<0 \mathrm{~m} \mathrm{~s}^{-1}$ (offshore directed) and increases for positive $u_{\mathrm{DU}}^{(1)}$ (onshore directed) to $n_{f}>1$ for $u_{\mathrm{DU}}^{(1)}>0.05 \mathrm{~m} \mathrm{~s}^{-1}$ (Fig. $8 \mathrm{~b}$ ). The bin-mean $\left|\nabla_{H} \rho\right|_{f}$ is also generally elevated for larger positive $u_{\mathrm{DU}}^{(1)}$ (Fig. 8b). The alongshore front binned-mean $n_{f}$ is not related to $V_{\mathrm{SB}}$ but weakly related to
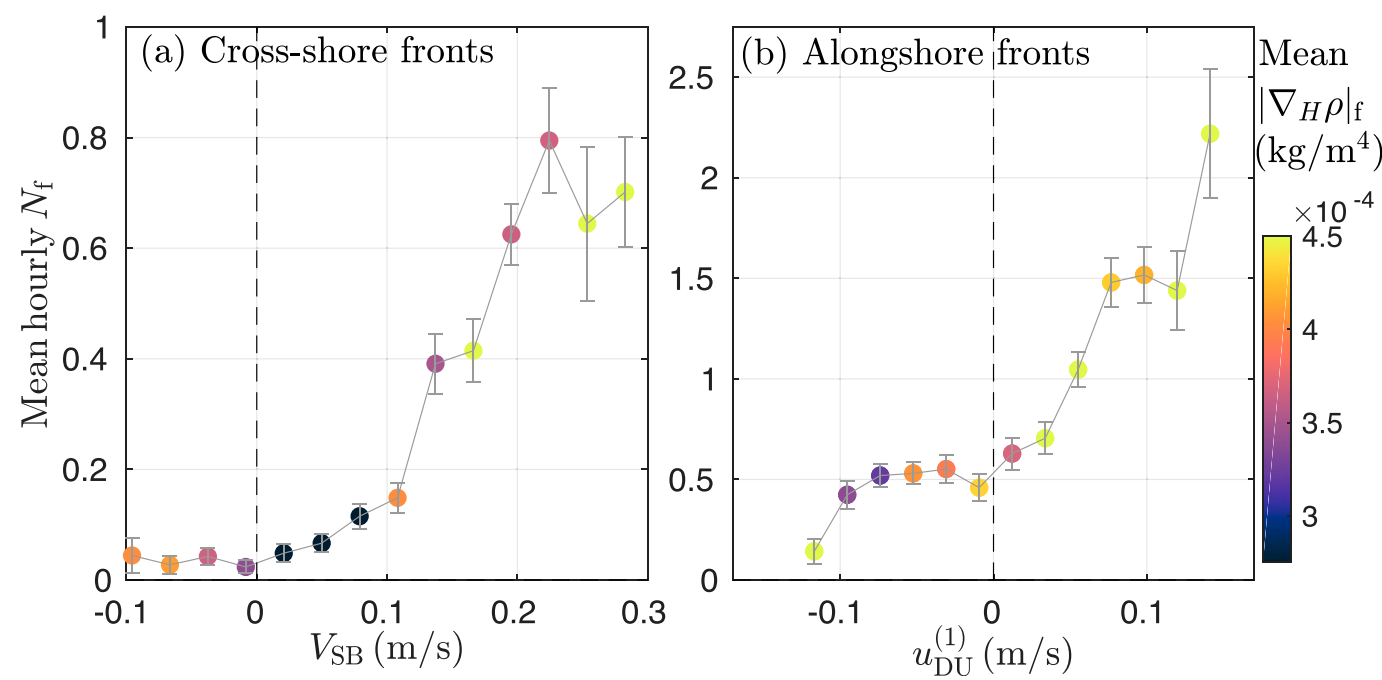

FIG. 8. (a) Bin-averaged hourly front count $n_{f}$ for the cross-shore fronts and the standard error (error bar) vs the subtidal alongshore velocity at $\mathrm{SB} V_{\mathrm{SB}}$. (b) Bin-averaged hourly $n_{f}$ for the alongshore fronts and the standard error (error bar) vs the diurnal-band first-mode surface cross-shore velocity $u_{\mathrm{DU}}^{(1)}$. In both (a) and (b), the color represents the bin-averaged $\left|\nabla_{H} \rho\right|_{f}$. 
the alongshore (grid aligned) subtidal wind stress with slightly elevated $n_{f}$ (and $\left|\nabla_{H} \rho\right|_{f}$ ) for the strongest downwelling winds versus strongest upwelling winds (not shown). Note, however, that winds were generally weak during the analysis period (Fig. 2b). This suggests that the alongshore fronts are forced by the onshore surface flow of diurnal baroclinic tides, which are significant in the region (W20) even though they are subcritical at this latitude.

\section{Ensemble mean cross-shore front}

Individual cross-shore fronts have variable orientation $\theta_{f}$, frontal length $L_{f}$, and frontal density gradient $\left|\nabla_{H} \rho\right|_{f}$. These fronts can be slightly curved, and the front may deviate from the front axis. To better understand the characteristics and dynamics of the cross-shore fronts, an ensemble mean crossshore front is created in the following analysis. Analysis of alongshore fronts will be further investigated elsewhere.

\section{a. Cross-shore front extraction, front decomposition, and ensemble average}

To diagnose ensemble cross-shore front dynamics, individual cross-shore fronts are first extracted, variables are decomposed into cross-front mean and perturbation components, and an ensemble mean cross-shore front is then generated on a subset of the cross-shore fronts. Each cross-shore front is extracted using a rectangular control volume, centered along the best-fit front axis, with horizontal dimensions of $4 \mathrm{~km}$ crossfront and $8 \mathrm{~km}$ alongfront where the onshore end of the control volume intersects the shoreline. Control volumes for the two example fronts are shown in Figs. $3 \mathrm{a}$ and $3 \mathrm{~b}$. Within the control volume, an alongfront coordinate ( $\tilde{x}$, positive onshore) is defined with $\tilde{x}=0$ at the shoreline intersection (Fig. 3b). The cross-front coordinate ( $\tilde{y}$, positive northward) is defined with $\tilde{y}=0$ at the front axis (see Fig. $3 b$ ). The origin $(\tilde{x}, \tilde{y})=(0,0) \mathrm{m}$ is on the shoreline (Fig. 3b). The flow is then decomposed into alongfront $(u)$ and cross-front $(v)$ components.

The extracted cross-shore fronts $\left(N_{f}=528\right.$, Fig. 6a) have a wide range of $\theta_{f}$. Some cross-shore fronts may interact with adjacent fronts detected at the same time. Most but not all crossshore fronts have a negative cross-front density gradient $\partial \rho / \partial \tilde{y}$ (section 3a). Ensemble analysis focuses on cross-shore fronts that do not interact with other fronts, have a smaller $\theta_{f}$ range, span across the inner to midshelf, and have a consistent cross-front density gradient sign. Thus, we generate a subset of cross-shore fronts, termed test fronts, that satisfy four additional criteria:

1) For a particular cross-shore front, all other fronts detected at the same time step must be separated by $>4 \mathrm{~km}$ (the control volume width). This criterion reduces the total cross-shore front count from 528 to 431.

2) Cross-shore fronts should be roughly shore-normal requiring the front orientation angle $\left(\theta_{f} \in\left[-25^{\circ}, 25^{\circ}\right]\right.$, removing an additional 299 fronts. A wider $\theta_{f}$ range (e.g., $\pm 45^{\circ}$ ) obtains consistent results for the subsequent analyses (not shown here).

3) The front must reach the $25-\mathrm{m}$ isobath (see Fig. 3b) and must span $-6<\tilde{x}<-4 \mathrm{~km}$ within the control volume (black contour in Fig. 3c), ensuring the front spans across

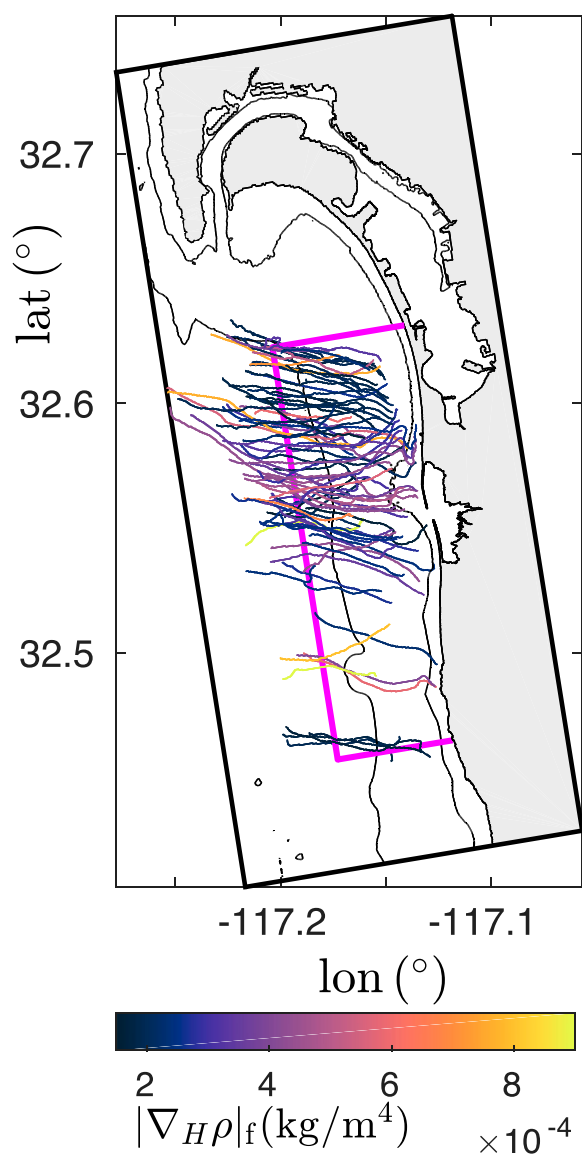

FIG. 9. Spatial distribution of the 86 cross-shore test fronts used to create the ensemble mean front with color representing $\left|\nabla_{H} \rho\right|_{f}$. Black contours denote the 10- and 25-m isobaths.

the inner to midshelf, and allowing an alongfront average over this region. This criterion excludes an additional 42 fronts.

4) To ensure consistent ensemble front dynamics, the crossfront density gradient $\partial \rho / \partial \tilde{y}$ must be negative, excluding four remaining fronts with positive $\partial \rho / \partial \tilde{y}$. These four fronts are associated with the northern side of cross-shoreoriented warm filaments that occur infrequently.

These criteria together result in a subset of 86 cross-shore test fronts (Fig. 9). The example cross-shore front in Fig. 3b is also a test front. The test fronts mostly tilt gently northward offshore, and their $\theta_{f}$ (red bar in Fig. 5a) are mostly negative with mean $( \pm \mathrm{std})$ of $-10.5^{\circ}\left( \pm 12.3^{\circ}\right)$. The test fronts are concentrated north of the TJRE mouth (Fig. 9). The test fronts have a mean $L_{f}=5.9 \mathrm{~km}$, similar to mean $L_{f}=5.8 \mathrm{~km}$ for all cross-shore fronts. In addition, the test fronts have a mean $\left|\nabla_{H} \rho\right|_{f}=3.5 \times 10^{-4} \mathrm{~kg} \mathrm{~m}^{-4}$, also similar to the mean of $3.9 \times$ $10^{-4} \mathrm{~kg} \mathrm{~m}^{-4}$ for all cross-shore fronts (section $3 \mathrm{a}$ ). This suggests that the 86 test fronts are representative of the set of all cross-shore fronts. Consistent with the entire set of crossshore fronts, test fronts occur (red line in Fig. 7b) only for $V_{\mathrm{SB}} \geq 0.08 \mathrm{~m} \mathrm{~s}^{-1}$ and also have stronger density gradient for 
$V_{\mathrm{SB}}>0.16 \mathrm{~m} \mathrm{~s}^{-1}$ (not shown). Among the test fronts, 56 fronts are from 17 fronts that are extracted at multiple (2-6) times as the front is advected. The other 30 fronts are unique and extracted only once. Overall, 47 unique fronts are included.

For each of the 86 test fronts, cross-front mean and perturbation components for variable $\psi_{i}$ (at each $z$ level if depth dependent) are defined as

$$
\psi_{i}(\tilde{x}, \tilde{y})=\bar{\psi}_{i}^{\tilde{y}}(\tilde{x})+\psi_{i}^{\prime}(\tilde{x}, \tilde{y})
$$

where $i$ denotes front number and $\overline{()^{\tilde{y}}}$ denotes a cross-front average over the 4-km-wide control volume, and the prime represents the perturbation. This decomposition is applied to the alongfront, cross-front, and vertical velocity components $(u, v, w)$, relative vertical vorticity $\zeta=\partial v / \partial \tilde{x}-\partial u / \partial \tilde{y}$, divergence $\delta=\partial u / \partial \tilde{x}+\partial v / \partial \tilde{y}$, temperature $T$, salinity $S$, density $\rho$, and sea surface elevation $\eta$. This decomposition for the surface density $\rho^{\prime}$ and perturbation $\left(u^{\prime}, v^{\prime}\right)$ vectors is shown for the cross-shore front example (Fig. 3c). The perturbation density $\rho^{\prime}$ has a strong cross-front gradient and weaker alongfront gradient, particularly in the region of the identified front $(-7<\tilde{x}<-1.5 \mathrm{~km}$, Fig. 3c). The front is also associated with a velocity convergence at the front axis $\tilde{y}=0 \mathrm{~m}$.

The individual test fronts can be complex, have variable orientations, and span a range of depths. To analyze a mean front, we ensemble average over all test fronts. The front ensemble mean, denoted with \langle\rangle , applied to the cross-front averaged and perturbation components, is estimated using all $N_{c}=86$ test fronts, for example, for $T^{\prime}$,

$$
\left\langle T^{\prime}\right\rangle(\tilde{x}, \tilde{y}, z)=\frac{1}{N_{c}} \sum_{i=1}^{N_{c}} T_{i}^{\prime} .
$$

The ensemble average [Eq. (3)] is estimated at a particular $(\tilde{x}, \tilde{y}, z)$ location only if $(\tilde{x}, \tilde{y}, z)$ is wet for all the 86 test fronts. This limits in particular the depth range over which the ensemble average can be estimated using all 86 test fronts. The ensemble average results in a smooth ensemble front as individual fronts are not straight. Note, an ensemble average generally implies averaging individual realizations drawn from the same random variable. However, these individual test fronts span 3 months, with varying winds, flows, and stratification (Fig. 2), and, as noted, are complex (Fig. 3c). Thus, these test fronts are unlikely to be members of the same random variable.

In some analyses that examine a vertical cross-front section, to further remove noise, an alongfront average across $-6<\tilde{x}<-4 \mathrm{~km}$, denoted with $\overline{()^{\tilde{x}}}$, of the ensemble mean variables is performed, for example,

$$
\overline{\left\langle T^{\prime}\right\rangle^{\tilde{x}}}(\tilde{y}, z)=\frac{1}{2 \mathrm{~km}} \int_{\tilde{x}=-6 \mathrm{~km}}^{\tilde{x}=-4 \mathrm{~km}}\left\langle T^{\prime}\right\rangle d \tilde{x},
$$

Recall that all test fronts are required to have a front within the range of $-6<\tilde{x}<-4 \mathrm{~km}$ (e.g., Fig. 3c).

\section{b. Ensemble and cross-front averaged test front}

The ensemble and cross-front mean variables represent the ensemble background shelf conditions associated with the test fronts (Fig. 10). The ensemble and cross-front mean sea surface
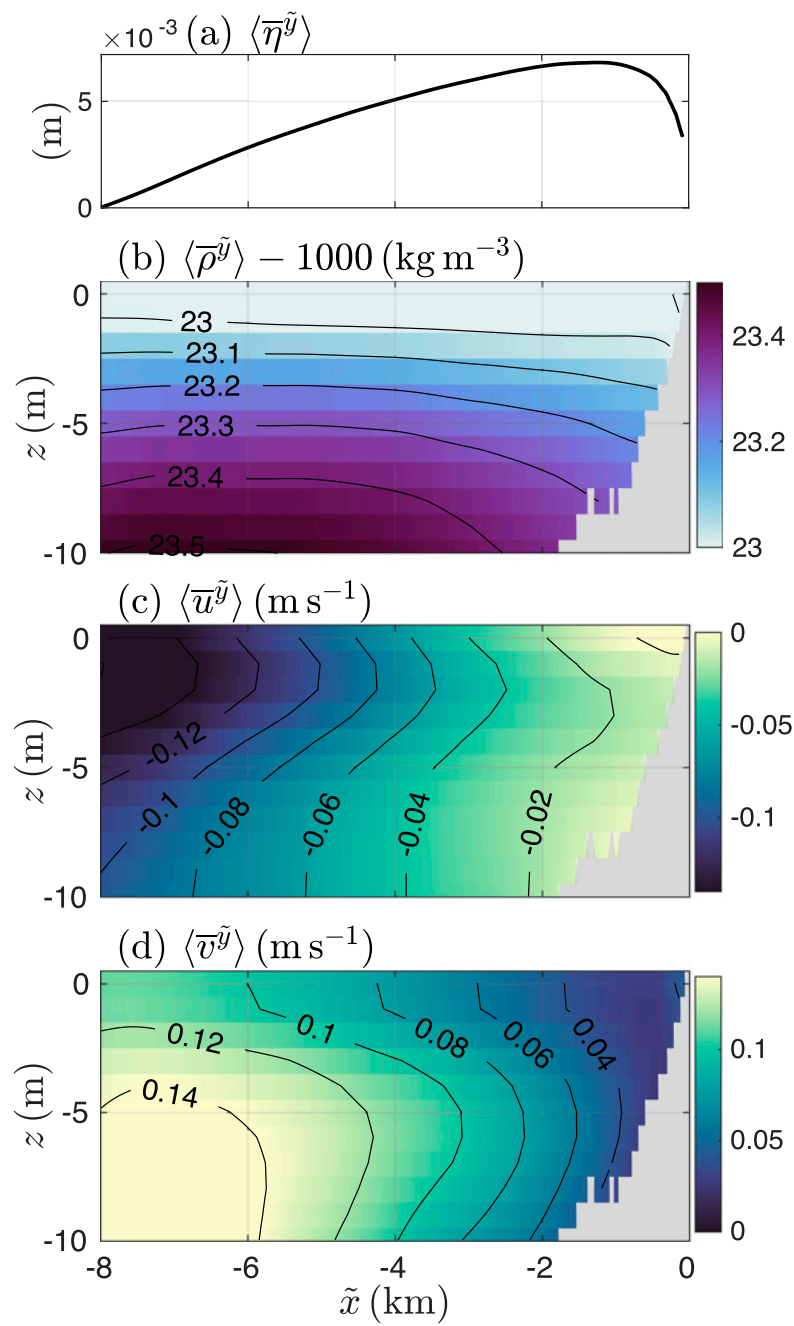

FIG. 10. (a) Ensemble and cross-front averaged sea surface elevation $\left\langle\bar{\eta}^{\bar{y}}\right\rangle$ vs alongfront direction $\tilde{x}$. Ensemble and cross-front averaged (b) density anomaly $\left\langle\bar{\rho}^{\tilde{y}}\right\rangle-1000 \mathrm{~kg} \mathrm{~m}^{-3}$, (c) alongfront velocity $\left\langle\bar{u}^{\tilde{y}}\right\rangle$, and (d) cross-front velocity $\left\langle\bar{v}^{\tilde{y}}\right\rangle$ as a function of $\tilde{x}$ and vertical $z$. Note, the gray shading denotes the cumulative bathymetry from the 86 test fronts.

elevation $\left\langle\bar{\eta}^{\tilde{y}}\right\rangle$ has a maximum near $\tilde{x} \approx-1.5 \mathrm{~km}$ and tilts downward farther offshore (alongfront) while steepening slightly (Fig. 10a). The ensemble and cross-front mean density $\left\langle\bar{\rho}^{\tilde{y}}\right\rangle$ varies from near-surface 1023.0 to $1023.5 \mathrm{~kg} \mathrm{~m}^{-3}$ at $z=$ $-10 \mathrm{~m}$ (Fig. 10b) with stratification stronger near surface $\left(N^{2} \approx\right.$ $6 \times 10^{-4} \mathrm{~s}^{-2}$ at $\left.z=-2 \mathrm{~m}\right)$ and weakening to $N^{2} \approx 3 \times 10^{-4} \mathrm{~s}^{-2}$ at $z=-10 \mathrm{~m}$. These values are consistent with the time mean top-to-bottom $N^{2}=3 \times 10^{-4} \mathrm{~s}^{-2}$ at SB in 30-m depth (Fig. 2c). The ensemble and cross-front mean currents $\left\langle\bar{u}^{\tilde{y}}\right\rangle$ and $\left\langle\bar{v}^{\tilde{y}}\right\rangle$ represent the ensemble background flow advecting the front (Figs. 10c,d). The alongfront component $\left\langle\bar{u}^{\tilde{y}}\right\rangle$ is offshore (alongfront) directed, weaker at depth, and strengthens offshore from $\approx-0.02 \mathrm{~m} \mathrm{~s}^{-1}$ at $\tilde{x}=-2 \mathrm{~km}$ to $\approx-0.12 \mathrm{~m} \mathrm{~s}^{-1}$ at $\tilde{x}=-8 \mathrm{~km}$ (Fig. 10c). The alongfront averaged (from $-8<\tilde{x}<-2 \mathrm{~km}$ ) alongfront divergence in the upper $10 \mathrm{~m}$ is $\partial\left\langle\bar{u}^{\tilde{y}}\right\rangle / \partial \tilde{x}=1.8 \times 10^{-5} \mathrm{~s}^{-1}(0.23 f)$. The cross-front component 

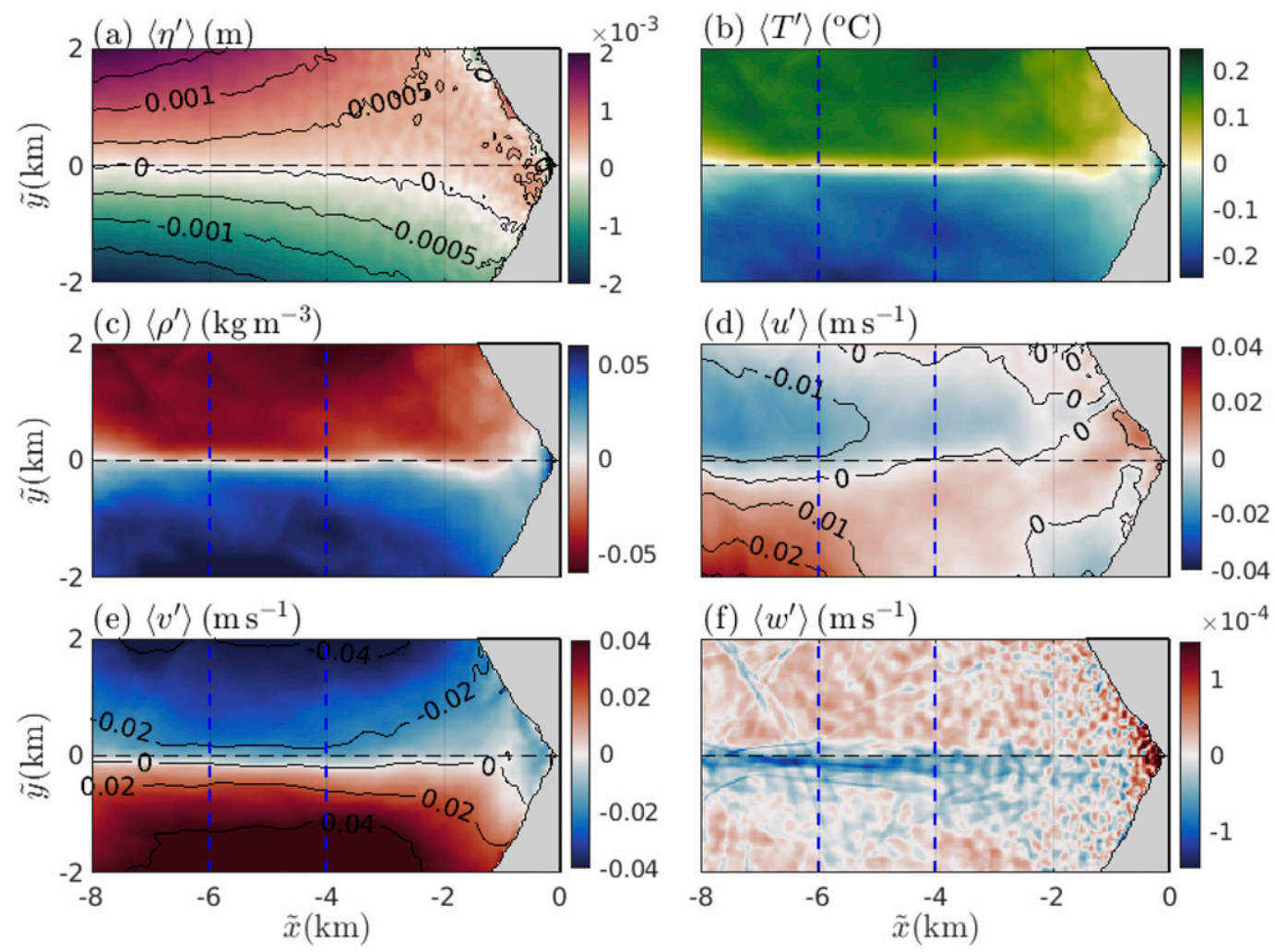

FIG. 11. Plan view of (a) the ensemble perturbation sea surface elevation $\left\langle\eta^{\prime}\right\rangle$, and the near surface (at $z=-1 \mathrm{~m}$ ) ensemble perturbation (b) temperature $\left\langle T^{\prime}\right\rangle$, (c) density $\left\langle\rho^{\prime}\right\rangle$, (d) alongfront velocity $\left\langle u^{\prime}\right\rangle$, (e) cross-front velocity $\left\langle v^{\prime}\right\rangle$, and (f) vertical velocity $\left\langle w^{\prime}\right\rangle$. The blue dashed lines delineate the region $(-6<\tilde{x}<-4 \mathrm{~km})$ for alongfront averaging. The gray shading denotes the cumulative land coverage from the 86 test fronts.

$\left\langle\overline{\boldsymbol{v}}^{\tilde{y}}\right\rangle$ is all positive (northward directed), maximum at $z \approx-5 \mathrm{~m}$, and strengthens offshore from $\left\langle\bar{v}^{\tilde{y}}\right\rangle \approx 0.06 \mathrm{~m} \mathrm{~s}^{-1}$ at $\tilde{x}=-2 \mathrm{~km}$ to $\left\langle\overline{\boldsymbol{v}}^{\tilde{y}}\right\rangle \approx 0.14 \mathrm{~m} \mathrm{~s}^{-1}$ at $\tilde{x}=-8 \mathrm{~km}$ (Fig. 10d). The depth-averaged $\left\langle\bar{v}^{\tilde{y}}\right\rangle$ is largely in balance with ensemble and cross-front averaged barotropic pressure gradient $(\mathrm{PG})$ induced by $\left\langle\bar{\eta}^{\tilde{y}}\right\rangle$ (Fig. 10a), consistent with classic cross-shelf depth-averaged momentum balances (e.g., Allen 1980).

The ensemble mean of the cross-front perturbation variables reveal a clear front that has dense $(-2<\tilde{y}<0 \mathrm{~km})$ and light $(0<\tilde{y}<2 \mathrm{~km})$ sides (Fig. 11a), strong cross-front gradients, and much weaker alongfront gradients. The perturbation $\left\langle\eta^{\prime}\right\rangle$ varies largely $\pm 0.001 \mathrm{~m}$ over the control volume (Fig. 11a). The strong cross-front gradient $\partial\left\langle\eta^{\prime}\right\rangle / \partial \tilde{y} \approx 10^{-6}$ is consistent with the offshore $\left\langle\bar{u}^{\tilde{y}}\right\rangle \approx-0.12 \mathrm{~m} \mathrm{~s}^{-1}$ (Fig. 10c) being largely in geostrophic balance. Weaker alongfront $\left\langle\eta^{\prime}\right\rangle$ gradient $\partial\left\langle\eta^{\prime}\right\rangle / \partial \tilde{x}$ has opposite signs on the dense and light side of the front. The near-surface $(z=-1 \mathrm{~m})$ perturbation temperature $\left\langle T^{\prime}\right\rangle$ varies strongly in the cross-front direction and much more weakly in the alongfront ( $\tilde{x})$ direction (Fig. 11b). In the main region of the front $(-6<\tilde{x}<-4 \mathrm{~km}),\left\langle T^{\prime}\right\rangle$ varies cross-front by $0.3^{\circ} \mathrm{C}$ within $\pm 0.5 \mathrm{~km}$ of the front axis. The cross-front perturbation density $\left\langle\rho^{\prime}\right\rangle$ is dominated by temperature (salinity not shown) and varies by $\approx 0.1 \mathrm{~kg} \mathrm{~m}^{-3}$ across $\pm 0.5 \mathrm{~km}$ of the front axis with gradient enhanced at the front axis (Fig. 11c). The perturbation alongfront velocity $\left\langle u^{\prime}\right\rangle$ is generally small $\left(0-0.02 \mathrm{~m} \mathrm{~s}^{-1}\right)$, much smaller than $\left\langle\bar{u}^{\tilde{y}}\right\rangle$, with decreasing magnitude toward the shoreline and switches sign on either side of the ensemble front (Fig. 11d). On both sides of the front, the spatial average of $\partial\left\langle u^{\prime}\right\rangle / \partial \tilde{x} \approx \pm 0.03 f$, much weaker than the spatial mean $\partial\left\langle\bar{u}^{\tilde{y}}\right\rangle / \partial \tilde{x} \approx 0.23 f$. The perturbation cross-front velocity $\left\langle\boldsymbol{v}^{\prime}\right\rangle$ varies from 0.04 to $-0.04 \mathrm{~m} \mathrm{~s}^{-1}$ from the dense to light side of the front (Fig. 11e), around one-third the magnitude of $\left\langle\overline{\boldsymbol{v}}^{\tilde{y}}\right\rangle$ (Fig. 10d). The maximum cross-front convergence $\partial\left\langle v^{\prime}\right\rangle / \partial \tilde{y} \approx-1.2 f$ occurs parallel to the front axis, but shifted slightly to the dense side $\tilde{y} \approx-0.3 \mathrm{~km}$, and is partially balanced by the divergence of the alongfront flow $\partial\left\langle\bar{u}^{\tilde{y}}\right\rangle / \partial \tilde{x}$. For $\tilde{x} \leq-4 \mathrm{~km}$, negative (downwelling) vertical velocity $\left\langle w^{\prime}\right\rangle \approx-1 \times$ $10^{-4} \mathrm{~m} \mathrm{~s}^{-1}$ occurs just on the dense side of the front axis $\left(-0.5<\tilde{y}<0 \mathrm{~km}\right.$, Fig. 11f). Farther from the front axis, $\left\langle w^{\prime}\right\rangle$ is mostly weakly positive.

To analyze the cross-front and vertical structure of the ensemble front, we additionally alongfront average ensemblemean perturbation variation within $-6<\tilde{x}<-4 \mathrm{~km}$ [e.g., $\overline{\left\langle T^{\prime}\right\rangle} \tilde{x}$ in Eq. (4), Fig. 12b]. Only the top $10 \mathrm{~m}$ is presented and analyzed as the test fronts minimum water depth at $\tilde{x}=-4 \mathrm{~km}$ is $13 \mathrm{~m}$. Many aspects of the upper water column $(z>-3 \mathrm{~m})$ alongfront averaged variables (Fig. 12) mirror those in Fig. 11. The ensemble front is generally enhanced near-surface (Fig. 12). The cross-front structure of $\overline{\left\langle S^{\prime}\right\rangle^{\tilde{x}}}$ has subsurface extrema (Fig. 12a). Cross-front salinity gradients contribute 


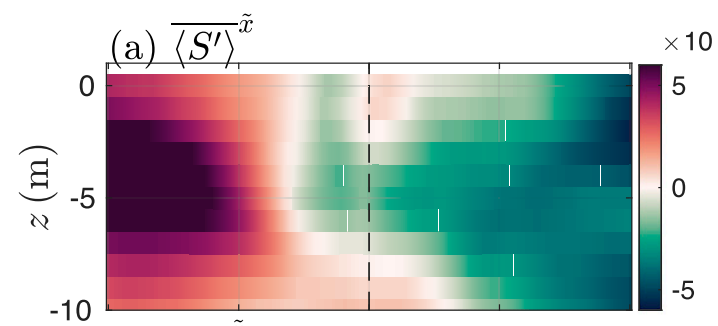$$
-10
$$$$
\text { (c) } \overline{\left\langle\rho^{\prime}\right\rangle} \tilde{x}\left(\mathrm{~kg} \mathrm{~m}^{-3}\right)
$$
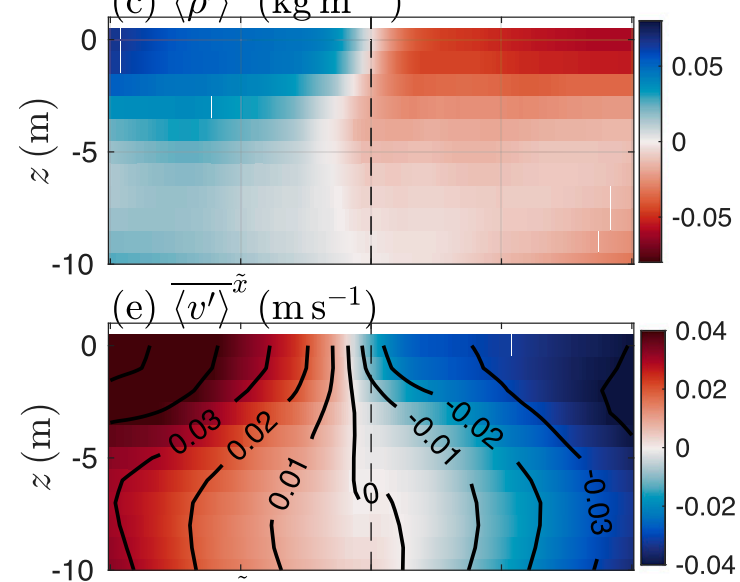

(g) $\overline{\left\langle\zeta^{\prime}\right\rangle} \tilde{x} / f$
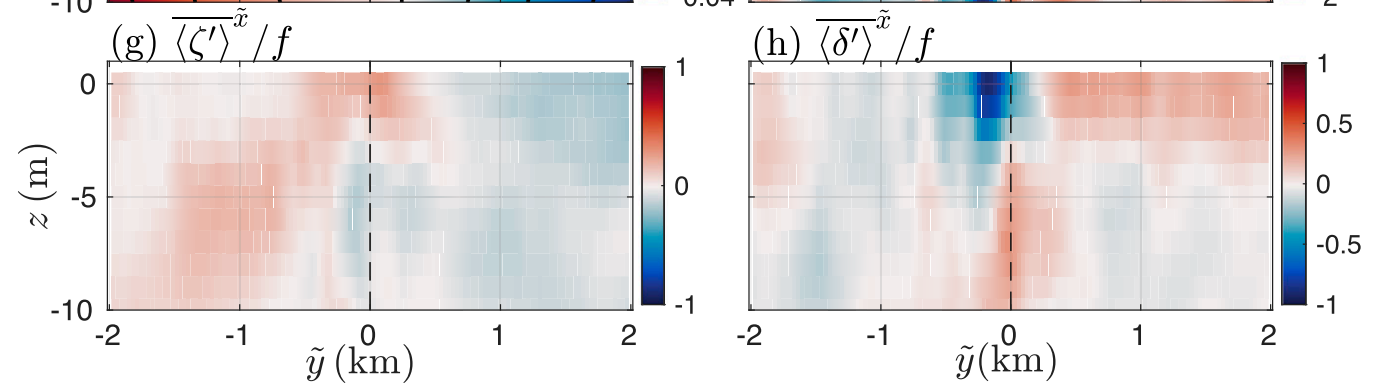
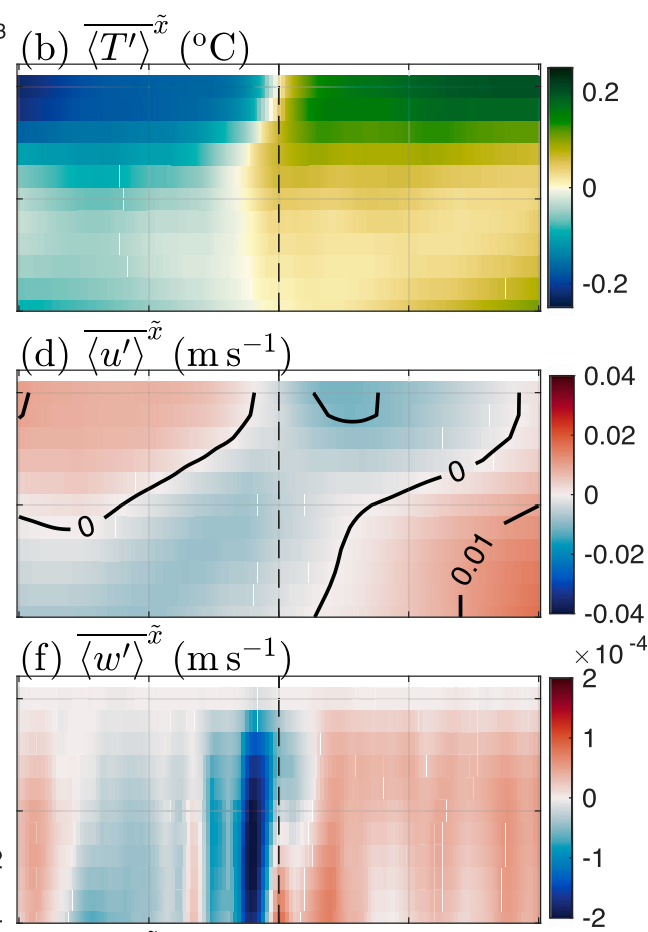

FIG. 12. Ensemble and alongfront $(-6 \leq \tilde{x} \leq-4 \mathrm{~km}$, see blue dashed lines in Fig. 11) averaged perturbation (a) salinity $\overline{\left\langle S^{\prime}\right\rangle}$, (b) temperature $\overline{\left\langle T^{\prime}\right\rangle^{x}}$, (c) density $\overline{\left\langle\rho^{\prime}\right\rangle^{\tilde{x}}}$, (d) alongfront velocity $\overline{\left\langle u^{\prime}\right\rangle^{\tilde{x}}}$, (e) cross-front velocity $\overline{\left\langle\boldsymbol{v}^{\prime}\right\rangle^{\tilde{x}}}$, (f) vertical velocity $\overline{\left\langle w^{\prime}\right\rangle^{\tilde{x}}}$, (g) normalized vertical vorticity $\overline{\left\langle\zeta^{\prime}\right\rangle^{\tilde{x}}} / f$, and (h) normalized divergence $\overline{\left\langle\delta^{\prime}\right\rangle^{\tilde{x}} / f \text { as a }}$ function of the cross-front $\tilde{y}$ and vertical $z$ coordinates over the top $10 \mathrm{~m}$ of the water column. The black dashed line marks the average front axis $(\tilde{y}=0 \mathrm{~km})$. Only the top $10 \mathrm{~m}$ is presented as the test fronts minimum water depth at $\tilde{x}=-4 \mathrm{~km}$ is $13 \mathrm{~m}$.

minimally to cross-front density gradients but act constructively with temperature. The cross-front temperature $\overline{\left\langle T^{\prime}\right\rangle^{\tilde{x}}}$ variability is reduced by $1 / 3$ between the upper $(z>-5 \mathrm{~m})$ and lower $(z<-5 \mathrm{~m})$ water column. The cross-front location $(\tilde{y})$ of maximum $\partial \overline{\left\langle T^{\prime}\right\rangle} \tilde{x} / \partial \tilde{y}$ is near the front axis at surface and shifts to $\tilde{y} \approx-0.5 \mathrm{~km}$ at $z=-5 \mathrm{~m}$ (Fig. 12b). The perturbation density $\overline{\left\langle\rho^{\prime}\right\rangle^{\tilde{x}}}$ (Fig. 12c) is consistent with $\overline{\left\langle T^{\prime}\right\rangle^{\tilde{x}}}$. The density gradient has a surface maximum at the front axis of $\partial \overline{\left\langle\rho^{\prime}\right\rangle^{\tilde{x}}} / \partial \tilde{y}=-1.9 \times 10^{-4} \mathrm{~kg} \mathrm{~m}^{-4}$, which decreases with depth and shifts to $\tilde{y} \approx-0.5 \mathrm{~km}$, similar to temperature. Within the top $5 \mathrm{~m}$, the perturbation alongfront velocity $\overline{\left\langle u^{\prime}\right\rangle^{\tilde{x}}}$ switches sign from dense $\left(\approx 0.01 \mathrm{~m} \mathrm{~s}^{-1}\right.$ at $\left.\tilde{y}<-0.5 \mathrm{~km}\right)$ to light $\left(\approx-0.01 \mathrm{~m} \mathrm{~s}^{-1}\right.$ ) sides of the front (Fig. 12d). For $z<-5 \mathrm{~m}$, the sign of $\overline{\left\langle u^{\prime}\right\rangle^{\tilde{x}}}$ reverses relative to near surface with diagonally sloped $\overline{\left\langle u^{\prime}\right\rangle^{\tilde{x}}}=0 \mathrm{~m} \mathrm{~s}^{-1}$ contours. The cross-front velocity $\overline{\left\langle\boldsymbol{v}^{\prime}\right\rangle^{\tilde{x}}}$ variability is also reduced by $\approx 1 / 3$ between the 
convergence weakens downward and reaches $-0.2 f$ at $z=-5 \mathrm{~m}$. Note that, at each $z$ level $\overline{\left\langle\delta^{\prime}\right\rangle^{\tilde{x}}}$ has a $\tilde{y}$ mean of 0 by definition, thus $\overline{\left\langle\boldsymbol{\delta}^{\prime}\right\rangle^{\tilde{x}}}$ can have positive values while $\overline{\left\langle\boldsymbol{v}^{\prime}\right\rangle^{\tilde{x}}}$ is consistently convergent over the 10-m water column (Fig. 12e).

The ensemble averaging of the 86 test fronts with variable lengths, density gradients, and deviation from a straight line results in some smoothing of the resulting ensemble front. We evaluate the smoothing by first examining the coincident parameters of the example front in Figs. $3 \mathrm{~b}$ and 3c. The example front density is also temperature dominated and has maximum density gradient $\overline{\partial \rho^{\prime} / \partial y^{\tilde{x}}}=-3.9 \times 10^{-4} \mathrm{~kg} \mathrm{~m}^{-4}$, a factor 2 times larger than the ensemble front maximum $\overline{\partial\left\langle\rho^{\prime}\right\rangle / \partial y^{x}}=-1.9 \times 10^{-4} \mathrm{~kg} \mathrm{~m}^{-4}$, as expected because the example front has a relatively strong density gradient (Fig. 5c). The example front cross-front variation in $\overline{u^{\prime}} \tilde{x}$ and $\bar{v}^{\prime} \tilde{x}$ are similar to the ensemble front but also a factor 2 times stronger. Using the ensemble mean definition (3), we define an ensemble standard deviation as $\operatorname{std}\left(T^{\prime}\right)=$ $\left[\left\langle\left(T^{\prime}-\left\langle T^{\prime}\right\rangle\right)^{2}\right\rangle\right]^{1 / 2}$. The ensemble standard deviation [e.g.,

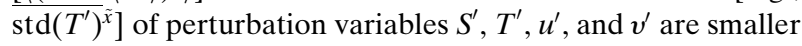
than but of the same order of the ensemble mean with little spatial structure, consistent with the quasi-exponential distribution of the cross-shore-oriented front parameters (Fig. 5c). The cross-front ensemble standard deviation density gradient $\overline{\operatorname{std}\left(\partial \rho^{\prime} / \partial \tilde{y}\right)^{\tilde{x}}}$ and divergence $\overline{\operatorname{std}\left(\delta^{\prime}\right)^{x}} \tilde{f}$ are elevated within $\pm 0.5 \mathrm{~km}$ of the front axis at magnitudes up to 1.5 times the ensemble mean and are weak elsewhere. This is also consistent with the quasi-exponential distribution of density gradient, suggesting that the ensemble mean front is not overly spatially smoothed.

\section{Ensemble front frontogenesis tendency}

The ensemble mean front exhibits a cross-front density gradient that extends nearly linearly 6-8 km offshore (Fig. 11). Frontogensis can occur through a variety of mechanisms including convergent cross-front flow (e.g., Hoskins and Bretherton 1972), horizontal shear (e.g., Dinniman and Rienecker 1999), and vertical mixing (e.g., Dewey and Moum 1990). Although the ensemble average does not resolve the front evolution history, we examine the local strengthening or weakening of the ensemble front and the responsible processes via a frontogenesis tendency equation analogous to Eq. (1). As $\tilde{y}$ is in the cross-front direction, we only consider the tendency of $\left(\partial \rho^{\prime} / \partial \tilde{y}\right)^{2}$ as

$$
\frac{D}{D t}\left[\left(\frac{\partial \rho^{\prime}}{\partial \tilde{y}}\right)^{2}\right]=F_{u}+F_{v}+F_{w}+F_{\text {vmix }},
$$

with

$$
\begin{aligned}
F_{u} & =-\frac{\partial u^{\prime}}{\partial \tilde{y}} \frac{\partial \rho}{\partial \tilde{x}} \frac{\partial \rho^{\prime}}{\partial \tilde{y}}, \\
F_{v} & =-\frac{\partial v^{\prime}}{\partial \tilde{y}}\left(\frac{\partial \rho^{\prime}}{\partial \tilde{y}}\right)^{2}, \\
F_{w} & =-\frac{\partial w^{\prime}}{\partial \tilde{y}} \frac{\partial \rho}{\partial z} \frac{\partial \rho^{\prime}}{\partial \tilde{y}}, \\
F_{\text {vmix }} & =\frac{\partial}{\partial \tilde{y}}\left[\frac{\partial}{\partial z}\left(K_{\nu} \frac{\partial \rho}{\partial z}\right)\right] \frac{\partial \rho^{\prime}}{\partial \tilde{y}},
\end{aligned}
$$

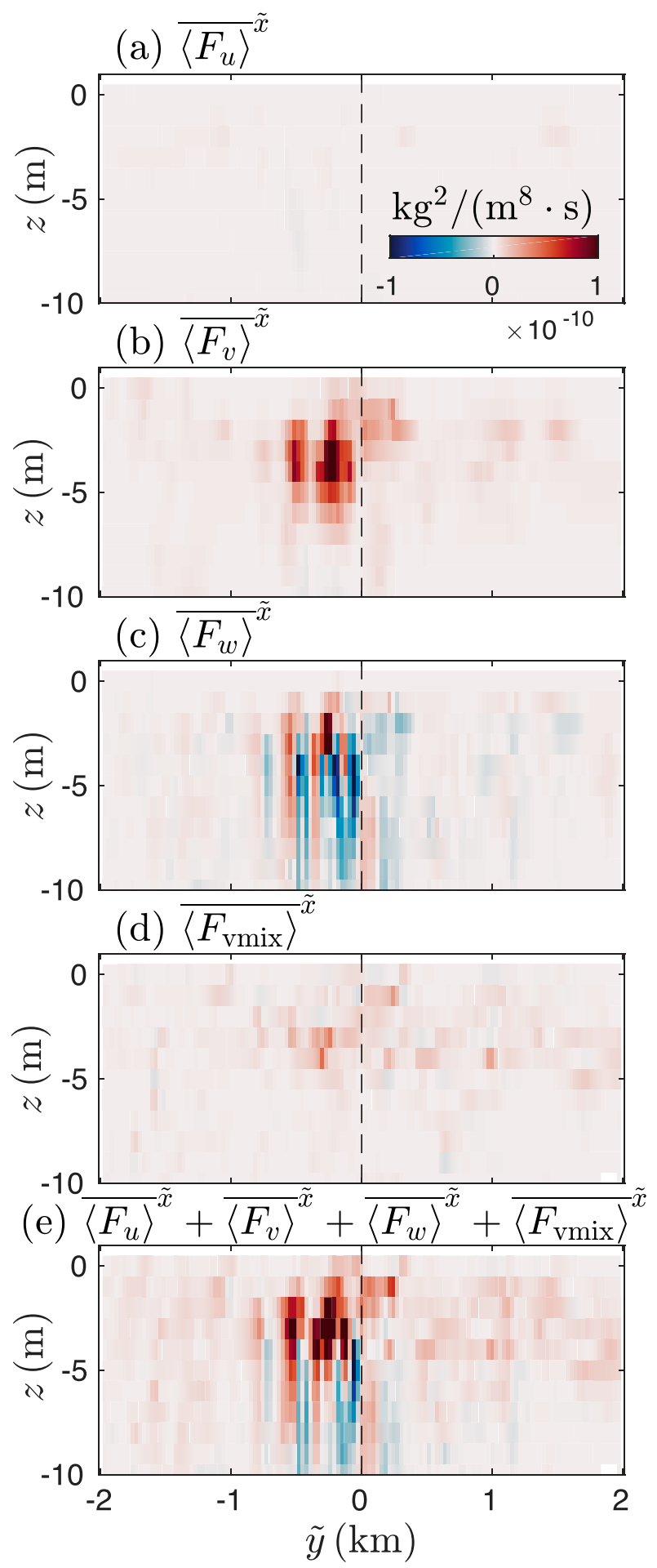

FIG. 13. Ensemble and alongfront $(-6<\tilde{x}<-4 \mathrm{~km})$ averaged frontogenesis tendency terms associated with (a) cross-front

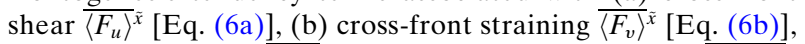
(c) vertical straining $\left\langle\overline{\left\langle F_{w}\right\rangle} \tilde{x}\right.$ [Eq. (6c)], (d) vertical mixing $\overline{\left\langle F_{\mathrm{vmix}}\right\rangle^{\tilde{x}}}$ [Eq. (6d)], and (e) the total sum as a function of $\tilde{y}$ and $z$. The black dashed line marks the average front axis. 
where $K_{\nu}$ is the modeled temporally and spatially varying eddy diffusivity derived from the $k-\epsilon$ scheme (e.g., Umlauf and Burchard 2003). Frontogenesis induced by the cross-front (horizontal) shear is denoted by $F_{u}$, and is zero for alongfront uniform density. The effect of convergent $v^{\prime}$ on frontogenesis is given by $F_{v}$. Vertical straining deformation is represented by $F_{w}$, and $F_{\text {vmix }}$ represents the effects of cross-front varying vertical mixing. The ensemble mean of each term is calculated for the 86 test fronts within the control volume and an alongfront average (within $-6<\tilde{x}<-4 \mathrm{~km}$ ) is then obtained (Fig. 13). Note, the ensemble mean frontogenesis terms are representative of the terms from the individual test fronts.

The cross-front shear induced $\overline{\left\langle F_{u}\right\rangle^{\tilde{x}}}$ is relatively small (Fig. 13a). Within the upper $10 \mathrm{~m}$ and $-2<\tilde{y}<2 \mathrm{~km}, \overline{\left\langle F_{u}\right\rangle^{\tilde{x}}}$ has a spatial rms 8-30 times smaller than the rms of the other three terms. This negligible $\overline{\left\langle F_{u}\right\rangle} \tilde{x}$ is due to the weak alongfront density variation $\partial \rho / \partial \tilde{x}$ (Fig. 11c). The cross-front straining deformation $\overline{\left\langle F_{v}\right\rangle} \tilde{x}$ is large and positive near the front axis $(-1<\tilde{y}<0.5 \mathrm{~km})$ where $\partial v^{\prime} / \partial \tilde{y}$ and $\partial \rho / \partial \tilde{y}$ are elevated, and is much weaker farther from the front axis (Fig. 13b). The vertical straining deformation term $\overline{\left\langle F_{w}\right\rangle^{\tilde{x}}}$ (Fig. 13c) is also large and mostly negative near the front axis $(-1<\tilde{y}<0.5 \mathrm{~km})$, and weak farther from the front axis. As $\partial \overline{\left\langle\rho^{\prime}\right\rangle} \tilde{x} / \partial \tilde{y}<0$ (Fig. 12c), the sign of $\overline{\left\langle F_{w}\right\rangle^{\tilde{x}}}$ is due to the mostly positive $\partial \overline{\left\langle w^{\prime}\right\rangle} \tilde{x} / \partial \tilde{y}$ (Fig. 12f) tilting the isopycnals toward the horizontal. The primarily negative $\overline{\left\langle F_{w}\right\rangle^{x}}$ largely counteracts the cross-front deformation term $\left.\overline{\left\langle F_{v}\right\rangle}\right\rangle^{\tilde{x}}$. The vertical mixing induced $\left.\overline{\left\langle F_{\text {vmix }}\right\rangle}\right\rangle^{\tilde{x}}$ (Fig. 13d) is relatively small, mostly positive, and is not concentrated near the front axis. Within $-1<\tilde{y}<0.5 \mathrm{~km}$, the spatial rms of $\left.\overline{\left\langle F_{\text {vmix }}\right\rangle}\right\rangle^{\tilde{x}}$ is one quarter that of $\left.\overline{\left\langle F_{v}\right\rangle}\right\rangle^{\tilde{x}}$ and $\overline{\left\langle F_{w}\right\rangle^{\tilde{x}}}$. The small

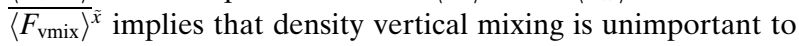

frontogenesis. The total frontogenesis tendency (Fig. 13e), primarily due to $\overline{\left\langle F_{v}\right\rangle} \tilde{x}+\overline{\left\langle F_{w}\right\rangle} \tilde{x}$, is mostly positive implying ensemble mean front strengthening concentrated in a narrow region $(-1<\tilde{y}<0.5 \mathrm{~km})$ near the front axis. Near the front axis $(-1<\tilde{y}<0.5 \mathrm{~km})$, the horizontally convergent flow (significant $\partial \overline{\left\langle w^{\prime}\right\rangle} \tilde{x} / \partial z$, Fig. 12f) and the large $\overline{\left\langle F_{w}\right\rangle} \tilde{x}$, indicate the importance of ageostrophic processes at the ensemble mean front. Note, the ensemble frontogenesis tendency terms only highlight the material derivative of the ensemble cross-front density gradient comprised of the 86 test fronts, and does not reveal which terms were important at times earlier or later.

\section{Ensemble front momentum balance}

For the perturbation velocity, no alongfront jet develops at the front axis (Fig. 12d), different from both the DF (Hoskins and Bretherton 1972) and TTW (McWilliams 2017) mechanisms, where an alongfront jet is in approximate thermal wind balance. The frontogenesis tendency analysis (Fig. 13) indicates the involvement of ageostrophic processes. In the DF and TTW mechanisms, an ageostrophic secondary cross-front flow $v_{a}$ is induced and the ageostrophic Coriolis forcing $f v_{a}$ is balanced by the alongfront material acceleration in the DF mechanism (Hoskins et al. 1978), and the vertical mixing in the TTW mechanism (McWilliams et al. 2015). Here the along-/crossfront momentum balances are examined and compared with these mechanisms.

Within the control volume, individual momentum terms in the $(\tilde{x}, \tilde{y})$ directions are decomposed into $\tilde{y}$ mean and perturbation components. The cross-front perturbation momentum balance equations in the $(\tilde{x}, \tilde{y})$ directions are

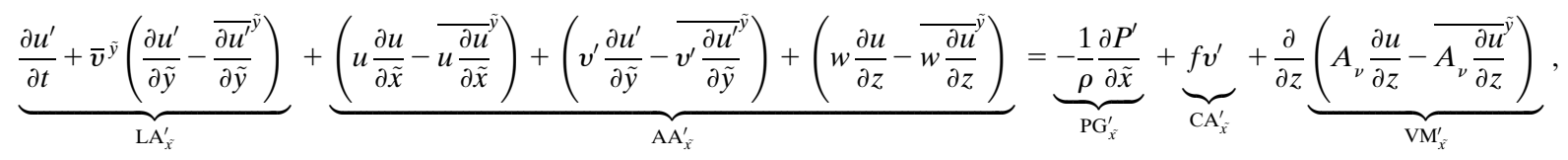

$\underbrace{\frac{\partial v^{\prime}}{\partial t}+\bar{v}^{\tilde{y}}\left(\frac{\partial v^{\prime}}{\partial \tilde{y}}-\frac{\overline{\partial v^{\prime}}}{\partial \tilde{y}}\right)}_{\mathrm{LA}_{\tilde{y}}^{\prime}}+\underbrace{\left(u \frac{\partial v}{\partial \tilde{x}}-\overline{u \frac{\partial v}{\partial \tilde{y}}}\right)+\left(v^{\prime} \frac{\partial v^{\prime}}{\partial \tilde{y}}-\overline{v^{\prime} \frac{\partial v^{\prime}}{\partial \tilde{y}}}\right)+\left(w \frac{\partial v}{\partial z}-\overline{w \frac{\partial v}{\partial z}}\right)}_{\mathrm{AA}_{\tilde{y}}^{\prime}}=\underbrace{-\frac{1}{\rho}\left(\frac{\partial P^{\prime}}{\partial \tilde{y}}-\frac{\overline{\partial P l^{\tilde{y}}}}{\partial \tilde{y}}\right)}_{\mathrm{PG}_{\tilde{y}}^{\prime}} \underbrace{-f u^{\prime}}_{\mathrm{CA}_{\tilde{y}}^{\prime}}+\frac{\partial}{\partial z} \underbrace{\left(A_{\nu} \frac{\partial v}{\partial z}-\overline{A_{\nu} \frac{\partial v}{\partial z}}\right)}_{\mathrm{VM}_{\tilde{y}}^{\prime}}$,

where the perturbation local acceleration $\left(\mathrm{LA}_{\tilde{x}}^{\prime}, \mathrm{LA}_{\tilde{y}}^{\prime}\right)$ incorporates the cross-front mean advection and represents the local acceleration of $\left(u^{\prime}, v^{\prime}\right)$ in a coordinate system moving with $\bar{v}^{\tilde{y}}$. The second term on the LHS denotes perturbation advective acceleration $\left(\mathrm{AA}_{\tilde{x}}^{\prime}, \mathrm{AA}_{\tilde{y}}^{\prime}\right)$. The three perturbation terms on the RHS are the pressure gradient $\left(\mathrm{PG}_{\tilde{x}}^{\prime}, \mathrm{PG}_{\tilde{y}}^{\prime}\right)$, Coriolis forcing $\left(\mathrm{CA}_{\tilde{x}}^{\prime}, \mathrm{CA}_{\tilde{y}}^{\prime}\right)$ and vertical mixing $\left(\mathrm{VM}_{\tilde{x}}^{\prime}, \mathrm{VM}_{\tilde{y}}^{\prime}\right)$, respectively. The ensemble and alongfront mean of each term in Eq. (7) is estimated (Figs. 14 and 15). To facilitate the comparison with the TTW and DF mechanisms, we decompose $\mathrm{CA}_{\tilde{x}}^{\prime}$ into a geostrophic component $f v_{g}^{\prime}$ that equals to $-\mathrm{PG}_{\tilde{x}}^{\prime}$, and an ageostrophic component $f v_{a}^{\prime}$ that equals to $\left(\mathrm{CA}_{\tilde{x}}^{\prime}+\mathrm{PG}_{\tilde{x}}^{\prime}\right)$. As the frontogenesis tendency is mostly within $-1<\tilde{y}<0.5 \mathrm{~km}$ (Fig. 13) and $\partial \overline{\left\langle\rho^{\prime}\right\rangle^{x}} / \partial \tilde{y}$ is much stronger over the upper $5 \mathrm{~m}$ (Fig. 12c), the following diagnostics emphasize the results within this $\tilde{y}$ and $z$ range. The ensemble mean momentum balance terms are representative of the momentum terms from the individual test fronts. Also, note that the ensemble mean momentum balance does not reveal what terms were important at times prior or after identification of a test front.

For the alongfront momentum terms in Eq. (7a), the perturbation Coriolis forcing $\overline{\left\langle\mathrm{CA}_{\tilde{x}}^{\prime}\right\rangle}$ (Fig. 14a) is the scaled $\overline{\left\langle\boldsymbol{v}^{\prime}\right\rangle^{\tilde{x}}}$ by definition (Fig. 12e). The perturbation alongfront pressure gradient $\overline{\left\langle\mathrm{PG}_{\tilde{x}}^{\prime}\right.} \tilde{x}$ (or $\left.-f \overline{\left\langle v_{g}^{\prime}\right\rangle} \tilde{x}\right)$ is mostly barotropic (Fig. 14b) 


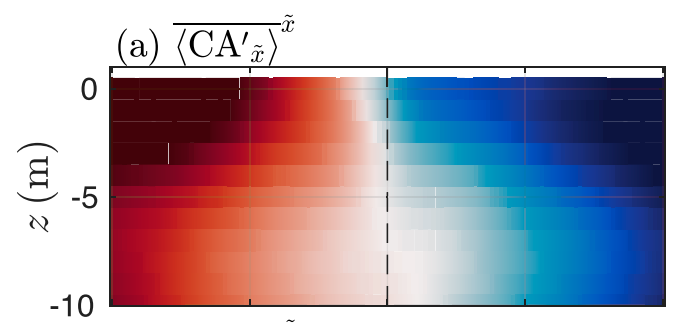

(b) $\overline{\left\langle\mathrm{PG}_{\tilde{x}}^{\prime}\right\rangle} \tilde{x}$

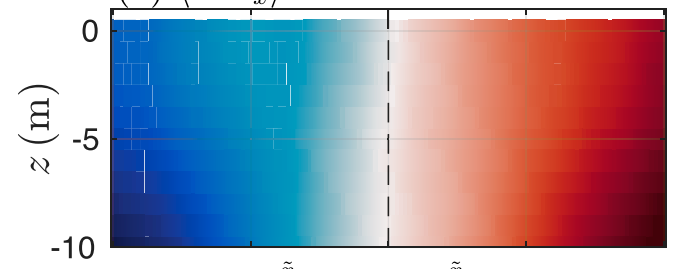

(c) $\overline{\left\langle\mathrm{CA}_{\tilde{x}}^{\prime}\right.} \bar{x}+\overline{\left\langle\mathrm{PG}_{\tilde{x}}^{\prime}\right\rangle} \tilde{x}$

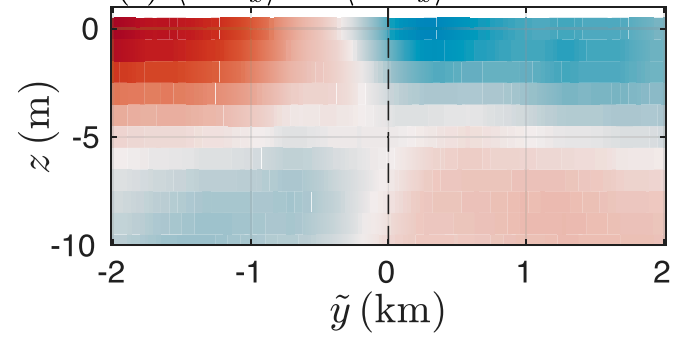

(d) $\overline{\left\langle\mathrm{LA}_{\tilde{x}}^{\prime}\right\rangle} \tilde{x}$
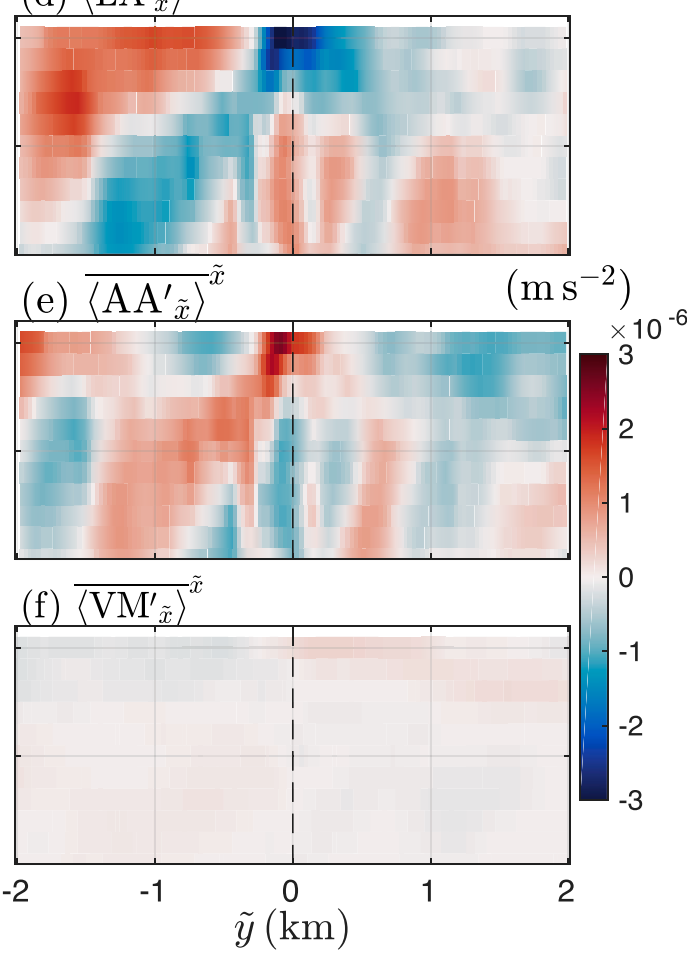

FIG. 14. Ensemble and alongfront $(-6<\tilde{x}<-4 \mathrm{~km})$ averaged perturbation momentum terms in the alongfront ( $\tilde{x}$ ) direction: (a) Coriolis forcing $\overline{\left\langle\mathrm{CA}_{\tilde{x}}^{\prime}\right\rangle^{x}}$, (b) pressure gradient $\overline{\left\langle\mathrm{PG}_{\tilde{x}}^{\prime}\right\rangle}$, (c) ageostrophic Coriolis forcing $\overline{\left\langle\mathrm{CA}_{\tilde{x}}^{\prime}\right\rangle} \tilde{\tilde{x}}+\overline{\left\langle\mathrm{PG}_{\tilde{x}}^{\prime} \bar{x}\right.}$, (d) local acceleration $\overline{\left\langle\mathrm{LA}_{\tilde{x}}^{\prime}\right\rangle}$, (e) advective acceleration $\overline{\left\langle\mathrm{AA}_{\tilde{x}}^{\prime}\right.}{ }^{x}$, and (f) vertical mixing $\overline{\left\langle\mathrm{VM}_{\tilde{x}}^{\prime}\right\rangle^{x}}$.

and increases northward as indicated from the $\left\langle\eta^{\prime}\right\rangle$ field (Fig. 11a). The corresponding geostrophic component $\overline{\left\langle\boldsymbol{v}_{g}^{\prime}\right\rangle} \tilde{x}$ decreases northward and $\partial \overline{\left\langle v_{g}^{\prime}\right\rangle} x / \partial \tilde{y}$ is largely spatially uniform, having a spatial mean ( \pm std $)$ of $-0.22 f( \pm 0.11 f)$ near the front axis $(-1<\tilde{y}<0.5 \mathrm{~km})$. The ageostrophic Coriolis forcing $\left(\overline{\left\langle\mathrm{PG}_{\tilde{x}}^{\prime}\right.} \tilde{x}+\overline{\left\langle\mathrm{CA}_{\tilde{x}}^{\prime}\right\rangle}\right)$ (or $\left.f \overline{\left\langle v_{a}^{\prime}\right\rangle} \tilde{x}\right)$ is an important contributor to the momentum budget within the upper $5 \mathrm{~m}$ (Fig. 14c). The convergence $\partial \overline{\left\langle v_{a}^{\prime}\right\rangle} \hat{x} / \partial \tilde{y}$ is primarily concentrated around the front axis. Within the upper $5 \mathrm{~m}$ and $-1<\tilde{y}<0.5 \mathrm{~km}$, the spatial mean $\partial \overline{\left\langle\boldsymbol{v}_{a}^{\prime}\right\rangle} \tilde{x} / \partial \tilde{y}=-0.17 f$ is comparable to the mean $\partial \overline{\left\langle\boldsymbol{v}_{g}^{\prime}\right\rangle} \tilde{x} / \partial \tilde{y}=-0.22 f$. Thus, both $\overline{\left\langle\boldsymbol{v}_{a}^{\prime}\right\rangle} \tilde{x}$ and $\overline{\left\langle\boldsymbol{v}_{g}^{\prime}\right\rangle} \tilde{x}$ are important contributors to the positive straining deformation $\left\langle F_{v}\right\rangle$ around the front axis (Fig. 13b). The ageostrophic Coriolis forcing $\overline{\left\langle\left\langle\boldsymbol{v}_{a}^{\prime}\right\rangle\right.} \tilde{\tilde{x}}$ (or $\overline{\left\langle\mathrm{PG}_{\tilde{x}}^{\prime}\right\rangle}+\overline{\left\langle\mathrm{CA}_{\tilde{x}}^{\prime}\right\rangle} \tilde{x}$, Fig. 14c) is nearly entirely balanced by the sum of the perturbation local and advective accelerations $\left(\overline{\left\langle\mathrm{LA}_{\tilde{x}}^{\prime}\right\rangle} \hat{x}+\overline{\left\langle\mathrm{AA}_{\tilde{x}}^{\prime}\right.} \bar{x}\right.$, Figs. 14d,e), as the perturbation vertical mixing $\frac{\left.\operatorname{VM}_{\tilde{x}}^{\prime}\right\rangle}{\hat{x}}$ is small (Fig. 14f). Within the upper $5 \mathrm{~m}$ and $-1<\tilde{y}<0.5 \mathrm{~km}$, the spatial $\mathrm{rms} \overline{\left\langle\mathrm{VM}_{\tilde{x}}^{\prime}\right\rangle} \tilde{x}$ is $7-14$ times smaller than the rms of the other terms. Within the upper $5 \mathrm{~m}$, $\overline{\left\langle\mathrm{LA}_{\tilde{x}}^{\prime}\right\rangle}$ is largely positive (negative) on the dense (light) side (Fig. 14d), indicating that the magnitude of the positive (negative) $\overline{\left\langle u^{\prime}\right\rangle^{\tilde{x}}}$ on the dense (light) side (Fig. 12d) increases as the ensemble mean front is strengthening (Fig. 13e). This acceleration is partially driven by $\overline{\left\langle\left\langle v_{a}^{\prime}\right\rangle\right.} \tilde{x}$ (Fig. 14c), with a sign determined by $\overline{\left\langle\mathrm{CA}_{\tilde{x}}^{\prime}\right\rangle}$ within the upper $5 \mathrm{~m}$ (Fig. 14a). The negligible $\overline{\left\langle\mathrm{VM}_{\tilde{y}}^{\prime}\right\rangle} \tilde{x}$ is different from the TTW balance (McWilliams et al. 2015) and many shallow water bathymetry-forced fronts (e.g.,
Simpson et al. 1978). The balance between the perturbation $f \overline{\left\langle v_{a}^{\prime}\right\rangle^{\tilde{x}}}$ and the perturbation material (local plus advective) acceleration is analogous to the DF alongfront balance (Hoskins et al. 1978).

For the cross-front momentum terms, the perturbation $\overline{\left\langle\mathrm{CA}_{\tilde{y}}^{\prime}\right.}{ }^{\tilde{x}}$ (Fig. 15a) reflects a scaled $\overline{\left\langle u^{\prime}\right\rangle^{\tilde{x}}}$ (Fig. 12d). The perturbation cross-front pressure gradient $\frac{\left\langle\mathrm{PG}_{\tilde{y}}^{\prime}\right\rangle}{x}$ has both barotropic and baroclinic contributions (Fig. 15b). At the front axis, the $\overline{\left\langle\mathrm{PG}_{\tilde{y}}^{\prime}\right\rangle}$ is negative at surface (directed to the light side, as indicated in Fig. 11a), and increases downward due to the negative cross-front density gradient $\left(\right.$ Fig. 12c)..$_{\tilde{x}}$ Clearly $\overline{\left\langle\mathrm{CA}_{\tilde{y}}^{\prime}\right\rangle} \hat{x}$ and $\overline{\left\langle\mathrm{PG}_{\tilde{y}}^{\prime}\right\rangle} \tilde{x}$ do not balance, and $\left(\overline{\left\langle\mathrm{CA}_{\tilde{y}}^{\prime}\right\rangle}{ }^{x}+\overline{\left\langle\mathrm{PG}_{\tilde{y}}^{\prime}\right.} \bar{x}^{x}\right)$ (Fig. 15c) is dominated by $\frac{\left\langle\mathrm{PG}_{\tilde{y}}^{\prime}\right\rangle}{\tilde{x}}$. As in the alongfront direction, the cross-front pressure gradient plus Coriolis acceleration is nearly entirely balanced by cross-front material acceleration $\left(\overline{\left\langle\mathrm{LA}_{\tilde{y}}^{\prime}\right\rangle} \tilde{x}_{\tilde{x}}+\overline{\left\langle\mathrm{AA}_{\tilde{y}}^{\prime}\right\rangle} \bar{x}\right)$, as crossfront perturbation vertical mixing $\overline{\left\langle\mathrm{VM}_{\tilde{y}}^{\prime}\right\rangle} \tilde{x}$ is small (Fig. 15f). Within $_{\tilde{x}}$ the upper $5 \mathrm{~m}$ and $-1<\tilde{y}<0.5 \mathrm{~km}$, the spatial rms $\overline{\left\langle\mathrm{VM}_{\tilde{y}}^{\prime}\right\rangle} \tilde{x}$ is 7 times smaller than the rms of $\overline{\left\langle\mathrm{PG}_{\tilde{y}}^{\prime}\right\rangle}{ }^{\tilde{x}}$ and the negligible perturbation vertical mixing in both directions further supports that the TTW mechanism does not hold here. Within the upper $5 \mathrm{~m}$, the local acceleration $\overline{\left\langle\mathrm{LA}_{\tilde{y}}^{\prime}\right\rangle} \tilde{x}$ is largely negative (positive) on the dense (light) side (Fig. 15d), implying that the magnitude of the positive (negative) $\overline{\left\langle\boldsymbol{v}^{\prime}\right\rangle^{\tilde{x}}}$ on the dense (light) side (Fig. 12e) decreases as the ensemble mean front is strengthening (Fig. 13e). This decrease is partially driven by $\left.\overline{\left\langle\mathrm{PG}_{\tilde{y}}^{\prime}\right.}\right\rangle^{\tilde{x}}$ within the upper $5 \mathrm{~m}$ (Fig. 15b).

Overall, the along-ensemble front ageostrophic balance is analogous to that in the DF mechanism (Hoskins et al. 1978; 


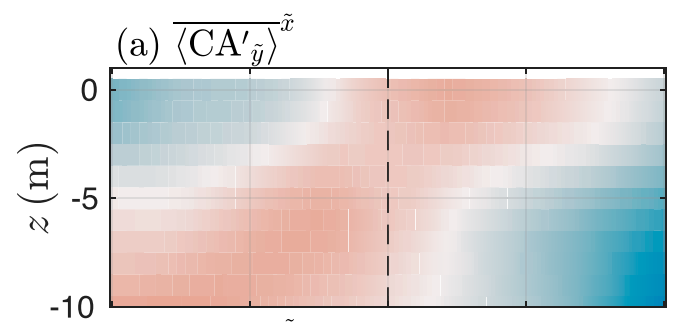

(b) $\overline{\left\langle\mathrm{PG}_{\tilde{y}}^{\prime}\right\rangle} \tilde{x}$

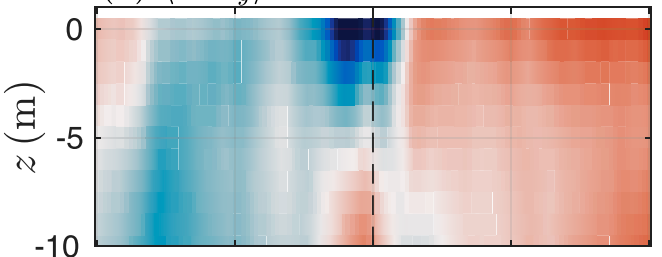

(c) $\left.\overline{\left\langle\mathrm{CA}^{\prime} \tilde{y}\right.}\right\rangle^{\tilde{x}}+\overline{\left\langle\mathrm{PG}_{\tilde{y}}^{\prime}\right.} \bar{x}^{\tilde{x}}$

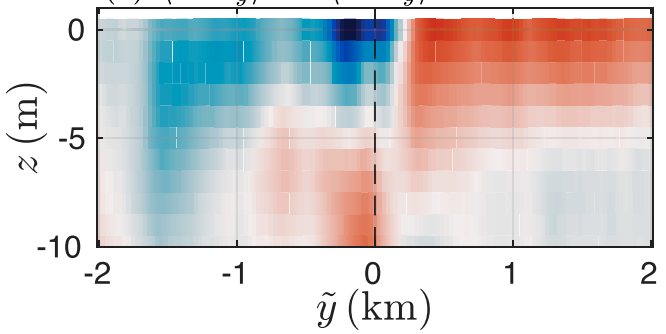

(d) $\overline{\left\langle\mathrm{LA}_{\tilde{y}}^{\prime}\right\rangle} \tilde{x}$
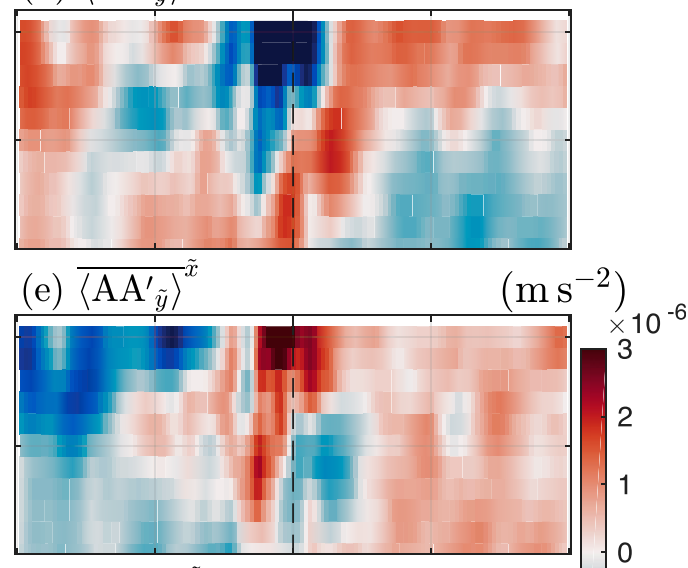

(f) $\overline{\left\langle\mathrm{VM}^{\prime} \tilde{y}\right.} \tilde{x}$

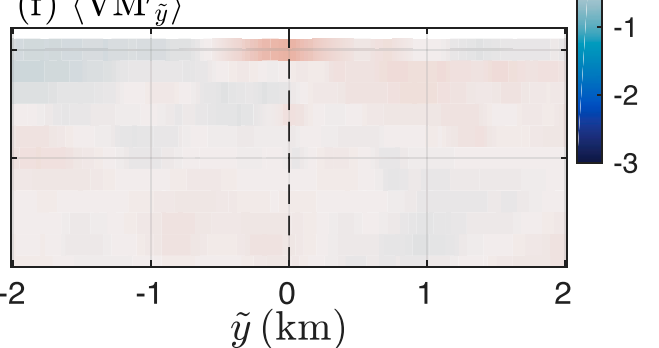

FIG. 15. As in Fig. 14, but for the perturbation momentum terms in the cross-front $(\tilde{y})$ direction: (a) Coriolis forcing $\left\langle\overline{\left\langle\mathrm{CA}_{\tilde{y}}^{\prime}\right.}\right\rangle_{\tilde{x}}$, (b) pressure gradient $\left\langle\mathrm{PG}_{\tilde{y}}^{\prime}\right\rangle^{x}$, (c) ageostrophic Coriolis forcing $\overline{\left\langle\mathrm{CA}_{\tilde{y}}^{\prime}\right.}{ }^{x}+{\overline{\left\langle\mathrm{PG}_{\tilde{y}}^{\prime}\right.}}^{\tilde{x}}$, (d) local acceleration $\overline{\left\langle\mathrm{LA}_{\tilde{y}}^{\prime}\right\rangle} \tilde{x}$, (e) advective acceleration $\overline{\left\langle\mathrm{AA}_{\tilde{y}}^{\prime}\right\rangle} \tilde{x}$, and (f) vertical mixing $\overline{\left\langle\mathrm{VM}_{\tilde{y}}^{\prime}\right\rangle} \tilde{x}$.

Thomas et al. 2008). One striking difference is that the ensemble front is not in cross-front geostrophic balance, whereas the DF mechanism has an approximate cross-front geostrophic balance (e.g., Hoskins and Bretherton 1972). The cross-front momentum balance between ${\overline{\left\langle\mathrm{PG}_{\tilde{y}}^{\prime}\right.}}^{\tilde{x}}$ and the material (local plus advective) acceleration is analogous to a nonlinear gravity wave (Sutherland 2010), which would have a sense of alongshore propagation. These results indicate that, the ensemble mean cross-shore-oriented front is ageostrophic, develops within a strain field, and is bounded by the shoreline (see onshore weakening $\left\langle u^{\prime}\right\rangle$ in Fig. 11d).

\section{Discussion}

\section{a. Coastal density front properties}

Within the 3-month analysis period, the density gradient magnitude and orientation contrast with previous studies. Here, the number of cross-shore fronts (with a $\pm 50^{\circ}$ range of $\theta_{f}$ ), is one-third that of alongshore fronts (Figs. 5a and 6). Even with taking the $\theta_{f}$ range into account, this contrasts with previous high $(75 \mathrm{~m})$ resolution coastal numerical model results (Dauhajre et al. 2017), where a cross-isobath density gradient was a factor 20 more probable than an along-isobath density gradient in depths $\leq 50 \mathrm{~m}$. Here, the subtidal stratification $N^{2}$ is relatively strong from $10^{-4}$ to $4 \times 10^{-4} \mathrm{~s}^{-2}$ (Fig. 2c), consistent with regional observations (e.g., Palacios et al. 2004). Although Dauhajre et al. (2017) do not report $N^{2}$, sections through springtime fronts and filaments allow inference of $N^{2} \approx$ $10^{-5} \mathrm{~s}^{-2}$, an order of magnitude weaker than the San Diego Bight simulation. The ensemble cross-shore front has crossfront density gradient $\overline{\left\langle\partial \rho^{\prime} / \partial \tilde{y} \hat{x}^{\tilde{x}}\right.} \approx 2 \times 10^{-4} \mathrm{~kg} \mathrm{~m}^{-4}$ (Fig. 11), roughly 1-4 times the modeled cross-front/filament density gradient for example fronts and filaments on the San Pedro shelf region (Dauhajre et al. 2017). These differences may be due to the differences in large-scale LV4 meridional density gradient (e.g., Huyer 1983; W20), the different study season (winter to spring versus summer to fall, here), the different headland-bay geometries (San Pedro region versus San Diego Bight), or the inclusion of surface gravity wave effects here. These model differences may also be due to grid resolution difference (i.e., 75 versus $\sim 30 \mathrm{~m}$ ) as submesoscale processes were better represented for 100- versus $36-\mathrm{m}$ grid resolution (resulting in shorter particle retentions; Dauhajre et al. 2019).

The horizontal density gradients here also are larger than deeper-water frontal horizontal density gradients of $O\left(10^{-4}\right)-$ $O\left(10^{-5}\right)$ observed in the CCS (Pallàs-Sanz et al. 2010; Johnson et al. 2020) over scales of $2-5 \mathrm{~km}$. These differences may be due to the background LV4 meridional density gradient, the general shoreward strengthening of surface horizontal density gradients from deep $(>500 \mathrm{~m})$ water to the shelf (e.g., Dauhajre et al. 2017), and the high ( $\sim 30 \mathrm{~m})$ grid resolution relative to $O(1) \mathrm{km}$ in observations.

Divergence and vorticity are also key front parameters. The ensemble cross-shore front has maximum divergence 
magnitude $\left|\overline{\left\langle\delta^{\prime}\right\rangle}\right| / f \approx 0.8$ similar to the $|\delta| / f \approx 2$ of the example modeled coastal fronts of Dauhajre et al. (2017). It is also similar to the $\delta / f \approx 0.7$ of Johnson et al. (2020) and $|\delta| / f \approx 0.4$ of Pallàs-Sanz et al. (2010) observed in the CCS. However, the ensemble cross-shore front vorticity $\left|\overline{\left\langle\zeta^{\prime}\right\rangle} \tilde{x}\right| / f \approx 0.2$ is rather small relative to $|\zeta| / f \approx 3$ of Dauhajre et al. (2017), likely due to front orientation differences (cross-shore here versus alongshore in Dauhajre et al. 2017) and also to smoothing induced by the ensemble. The ensemble cross-shore front vorticity is also weaker than the $|\zeta| / f \approx 0.7$ observed in CCS fronts (Pallàs-Sanz et al. 2010; Johnson et al. 2020). These CCS fronts are not shoreline boundary impacted, and in total this suggests that cross-shoreoriented fronts have reduced vorticity (relative to divergence) due to the shoreline boundary limiting alongfront velocity.

Spatial distribution of the $N_{f}=528$ cross-shore fronts shows a concentration $(\approx 2 / 3$ of the fronts) to the north of the TJRE mouth (Fig. 6a2), suggesting that the TJRE shoal may be a factor in promoting cross-shore front generation, as $V_{\mathrm{SB}}$ is mostly positive (northward directed). The alongshore front occurrence frequency is elevated with onshore directed surface diurnal baroclinic flow $u_{\mathrm{DU}}^{(1)}$ (Fig. 8b). When $u_{\mathrm{DU}}^{(1)}$ is onshore, surface convergence occurs due to the shoreline boundary. For the alongshore fronts, the cross-front density gradient is positive (warmer water offshore) about $2 / 3$ of the time. This suggests that the alongshore fronts are often, but not always, onshore propagating internal near-surface warm bores (e.g., Colosi et al. 2018; McSweeney et al. 2020) transformed from the diurnal internal tides. At this study site, a nonlinear diurnal internal tide was observed to enhance an alongshore tracer front within $1 \mathrm{~km}$ of shore (Grimes et al. 2020). This result may be seasonal and depend on the details of the stratification. Additionally, analysis of surface density fronts would obscure near-bed internal cold bores (e.g., Moum et al. 2007; Sinnett et al. 2018).

\section{b. Comparison with the TTW and DF mechanisms}

The TTW mechanism has been invoked to explain density filament generation in specific case studies (e.g., Gula et al. 2014; Dauhajre et al. 2017). A case study of two Gulf Stream density filaments showed that ageostrophic Coriolis forcing is balanced by the vertical mixing (Gula et al. 2014). Another case study of two density filaments and fronts in 20-30-m water depth on the shelf with wind stress $\sim 0.03 \mathrm{~N} \mathrm{~m}^{-2}$ found that the horizontal flow field is consistent with the TTW dynamics (Dauhajre et al. 2017). This wind stress was roughly a factor of 3 times stronger than the typical subtidal wind stress $\sim 0.01 \mathrm{~N} \mathrm{~m}^{-2}$ in the San Diego Bight simulations, implying wind speeds 1.7 times stronger, consistent with regional spring to fall differences (e.g., Winant and Dorman 1997; Dong et al. 2009). These case studies analyzed individual hand-selected filaments, in contrast to the ensemble front that comprises 86 test fronts.

As the regional winds are relatively weak and the stratification is strong, we examine whether the TTW mechanism is appropriate for the ensemble front. Utilizing the TTW scaling [Eq. (4.5) of McWilliams 2017]

$$
v_{\mathrm{ttw}}=\frac{A_{v} g|\partial \rho / \partial y|}{\rho_{0} f^{2} d},
$$

with characteristic ensemble front $\left|\partial\left\langle\rho^{\prime}\right\rangle / \partial \tilde{y}\right|=1.9 \times 10^{-4} \mathrm{~kg} \mathrm{~m}^{-4}$, vertical thickness $d \approx 10 \mathrm{~m}$, and characteristic (vertically averaged over $10 \mathrm{~m}$ ) model vertical eddy viscosity $A_{v}=2 \times$ $10^{-3} \mathrm{~m}^{2} \mathrm{~s}^{-1}$, yields a cross-front ageostrophic velocity of $v_{\mathrm{ttw}}=$ $0.05 \mathrm{~m} \mathrm{~s}^{-1}$, a value somewhat larger than $\left\langle\boldsymbol{v}^{\prime}\right\rangle$, a priori indicating TTW dynamics could be active. However, TTW dynamics do not apply to the ensemble front. The ensemble front shows weak perturbation vertical mixing $\overline{\left\langle\mathrm{VM}_{\tilde{x}}^{\prime}\right\rangle} \hat{x}$ and $\overline{\left\langle\mathrm{VM}_{\tilde{y}}^{\prime}\right\rangle} \hat{x}$ [Eqs. (7a) and (7b), Figs. 14f and 15f], indicating that the TTW mechanism is not active in the ensemble front. Furthermore, an idealized TTW generated density front consists of an alongfront jet in thermal wind balance and a weaker ageostrophic alongfront flow $u_{a}$ that is induced by the cross-front vertical mixing and has an extremum at the front (McWilliams 2017). Here $\left\langle u^{\prime}\right\rangle$ is ageostrophic, varies sign across the front, and has no extrema at the front (Fig. 11d). In the TTW mechanism, the vertical shear of the thermal wind balanced alongfront jet induces alongfront vertical mixing (McWilliams 2017), but generally requires strong vertical mixing (strong wind forcing which is absent here). In the cross-front direction, the ensemble front is not in a thermal wind balance as in the upper $5 \mathrm{~m}$ and $-1<\tilde{y}<0.5 \mathrm{~km}$, rms of $\partial \overline{\left\langle u^{\prime}\right\rangle^{\tilde{x}}} / \partial z \approx 2 \times 10^{-3} \mathrm{~s}^{-1}$ (Fig. 12d), is about one quarter the rms of $g /\left(\rho_{0} f\right)\left(\partial \overline{\left\langle\rho^{\prime}\right\rangle} \tilde{x} / \partial \tilde{y}\right) \approx 8 \times 10^{-3} \mathrm{~s}^{-1}$, predicted from a thermal wind balance. This weak vertical shear is consistent with the weak vertical mixing of momentum $\overline{\left\langle\mathrm{VM}_{\tilde{x}}^{\prime}\right\rangle^{x}}$ (Fig. 14f).

In the DF mechanism, the large-scale strain field is nondivergent and in geostrophic balance (e.g., Hoskins and Bretherton 1972; McWilliams 2017). Here, $\left\langle\bar{u}^{\tilde{y}}\right\rangle$ is divergent and largely in geostrophic balance within $-6<\tilde{x}<-4 \mathrm{~km}$ (Fig. 10c). The geostrophic component of the perturbation cross-front flow $\overline{\left\langle v_{g}^{\prime}\right\rangle} \tilde{x}$ is largely uniformly convergent over the $(\tilde{y}, z)$ domain (Fig. 14b). Within the upper $10 \mathrm{~m}$ and $-2<\tilde{y}<2 \mathrm{~km}$, the mean cross-front convergence $\partial \overline{\left\langle v_{g}^{\prime}\right\rangle} \tilde{x} / \partial \tilde{y} \approx-0.21 f$ (Fig. 14b) is largely balanced by the mean alongfront divergence $\partial\left\langle\bar{u}^{\tilde{y}}\right\rangle / \partial \tilde{x} \approx 0.25 f$ within the same region (Fig. 10c). Thus, $\left(\left\langle\bar{u}^{\tilde{y}}\right\rangle,\left\langle v_{g}^{\prime}\right\rangle\right)$ are largely nondivergent and in geostrophic balance, analogous to the large-scale DF strain field. The $\left\langle v_{g}^{\prime}\right\rangle$ convergence may be partially due to the LV4 irregular topography (i.e., curved coast). Flow convergence induced by varying topography (e.g., varying river channel width) has been found important for estuarine frontogenesis (e.g., Geyer and Ralston 2015). Embedded within the DF strain field, the DF-mechanism ASC has a mass balance where the cross-front convergence is balanced by the downwelling (e.g., Hoskins 1982; Thomas et al. 2008). Within the frontogenesis region (i.e., $z>-5 \mathrm{~m}$ and $-1<\tilde{y}<0.5 \mathrm{~km})$, the mean ageostrophic cross-front convergence $\partial \overline{\left\langle\boldsymbol{v}_{a}^{\prime}\right\rangle} \tilde{x} / \partial \tilde{y} \approx-0.17 f$ (Fig. 14c) is largely balanced by the mean perturbation vertical divergence $\partial \overline{\left\langle w^{\prime}\right\rangle} \tilde{x} / \partial z \approx 0.10 f$ (Fig. 12f). Thus, $\left(\left\langle v_{a}^{\prime}\right\rangle,\left\langle w^{\prime}\right\rangle\right)$ are analogous to the ASC in the DF mechanism. Despite these similarities in mass conservation, the momentum balances fundamentally differ. The DF mechanisms ASC is semigeostrophic with a cross-front geostrophic balance and an alongfront ageostrophic balance. However, the ensemble front has an opposite balance: the perturbation cross-front momentum balance is ageostrophic (Fig. 15), whereas the alongfront momentum balance is largely geostrophic (Fig. 14). 
This difference in DF-mechanism ASC and ensemble crossshore front perturbation momentum balances may be due to the presence of a shoreline boundary. Coastal circulation also is largely semigeostrophic (e.g., Allen 1980; Lentz et al. 1999), particularly at subtidal time scales, with largely geostrophic cross-shore momentum balance and largely ageostrophic alongshore balance as wind forcing and nonlinear advection can become important. For open ocean fronts, the alongfront flow is unbounded and the cross-front momentum balance can be consistent with a geostrophic (thermal wind) balance. Here the ensemble cross-shore front is constrained by the shoreline and the associated semigeostrophic momentum balance becomes more consistent with that of coastal circulation. In the end, cross-front convergence is key across various types of surface density fronts from the unbounded TTW and DF to the shoreline-bounded ensemble cross-shore front here, albeit via different dynamics.

\section{c. The cross-front ageostrophic balance: Relationship to a gravity current}

The primary cross-front momentum balance between the perturbation $\overline{\left\langle\mathrm{PG}_{\tilde{y}}^{\prime}\right\rangle} \tilde{x}$ and the material acceleration $\overline{\left\langle\mathrm{LA}_{\tilde{y}}^{\prime}\right\rangle} \tilde{x}+\overline{\left\langle\mathrm{AA}_{\tilde{y}}^{\prime}\right\rangle} \tilde{x}$ (Fig. 15) is that of a nonlinear gravity wave (e.g., Sutherland 2010). In the limit of small $\mathrm{LA}_{\tilde{y}}^{\prime}$, a $\mathrm{PG}_{\tilde{y}}^{\prime}$ and $\mathrm{AA}_{\tilde{y}}^{\prime}$ balance is that of a gravity current (e.g., Benjamin 1968). Here, within $z>-5 \mathrm{~m}$ and $-1<\tilde{y}<0.5 \mathrm{~km}$, the $\mathrm{rms}$ of $\left.\overline{\left\langle\mathrm{LA}_{\tilde{y}}^{\prime}\right.}\right\rangle^{\hat{x}}(1.9 \times$ $\left.10^{-6} \mathrm{~kg} \mathrm{~m}^{-4}\right)$ and $\overline{\left\langle\mathrm{AA}_{\tilde{y}}^{\prime}\right\rangle}\left(1.3 \times 10^{-6} \mathrm{~kg} \mathrm{~m}^{-4}\right)$ are comparable (Fig. 15), and the ensemble front may propagate as a gravity current or a nonlinear gravity wave. Density fronts propagating as gravity currents have been observed in the open ocean with density difference $\Delta \rho$ of $0.2-0.5 \mathrm{~kg} \mathrm{~m}^{-3}$ (e.g., Johnson 1996; Warner et al. 2018). The transition from a geostrophically balanced open-ocean front to a gravity current has been modeled with resulting $\Delta \rho$ of $0.1-0.3 \mathrm{~kg} \mathrm{~m}^{-3}$ (Warner et al. 2018; Pham and Sarkar 2018).

The ensemble cross-shore front has similarities with coastal buoyant plume fronts that typically have order of magnitude larger density gradients (e.g., Lentz et al. 2003). Both are crossshore-oriented, shoreline bounded, and have a cross-front ageostrophic balance. Modeled coastal buoyant plumes with much larger density gradients have gravity current dynamics (e.g., Akan et al. 2018). In Lentz et al. (2003), the observed plume front propagates alongshore from the light toward the dense side with a cross-front density difference $\Delta \rho \approx$ $3.0 \mathrm{~kg} \mathrm{~m}^{-3}$ over $2 \mathrm{~km}$, and propagation speed reaching $\approx 0.5 \mathrm{~m} \mathrm{~s}^{-1}$. For the ensemble front, cross-front density difference $\Delta\left\langle\rho^{\prime}\right\rangle \approx-0.08 \mathrm{~kg} \mathrm{~m}^{-3}$ over $1 \mathrm{~km}$ (Fig. 11c), 37 times weaker than the Lentz et al. (2003) plume front. Assuming that the ensemble front represents a two-layer gravity current in $h=20$-m depth with an upper (lower) layer depth of $h_{1}=5 \mathrm{~m}$ $\left(h_{2}=15 \mathrm{~m}\right)$, the corresponding gravity current speed is $-\sqrt{g^{\prime} h_{1} h_{2} /\left(h_{1}+h_{2}\right)} \sim-0.05 \mathrm{~m} \mathrm{~s}^{-1}$ (i.e., southward). This suggest that the ensemble cross-shore front with its weak density gradient propagates as a southward gravity current embedded within the northward large-scale flow $\left(\left\langle V_{\mathrm{SB}}\right\rangle \approx 0.2 \mathrm{~m} \mathrm{~s}^{-1}\right.$, Figs. 7a,b) and the resulting northward $\left\langle\overline{\boldsymbol{v}}^{\tilde{y}}\right\rangle \sim 0.1 \mathrm{~m} \mathrm{~s}^{-1}$ (Fig. 10d) likely reflects the net sum of the northward largescale advection and southward gravity current propagation.
We next explore why the ensemble cross-shore front (made up of the 86 test fronts) has dynamics similar to a gravity current. Modeled density fronts in geostrophic balance can transform into gravity currents for similar density differences as seen here (Warner et al. 2018; Pham and Sarkar 2018). However, the shoreline boundary constrains the cross-shore flow preventing cross-shore-oriented fronts from being in neargeostrophic balance, as suggested by the cross-front momentum balance. Note that alongshore-oriented fronts, such as the example close to a headland in Dauhajre et al. (2017), have no such limitation. Near-field river plumes behave like gravity currents but for distances larger than a Rossby deformation radius $L_{R}=N h / f$ other dynamics are important. The crossshore fronts are $7-18 \mathrm{~km}$ from the SDB mouth, and using $N^{2}=$ $2 \times 10^{-4} \mathrm{~s}^{-2}$ and $h=25 \mathrm{~m}$ results in $L_{R} \approx 4.5 \mathrm{~km}$. This and the lack of relationship between cross-shore frontal occurrence and SDB outflow indicate that the cross-shore fronts are not gravity currents directly forced by the SDB outflow.

The modeled San Diego Bight region has a weak (a factor of 30 times smaller than the ensemble cross-shore front) largescale alongshore density gradient (W20) due to regional upwelling gradients (e.g., Huyer 1983) and warm water outflow from the SDB. W20 noted that the northward directed subtidal depth-averaged alongshore flow along the $\approx 25$-m isobath was convergent with divergence of $\approx-0.05 f$, much weaker than the divergence of the ensemble front. However, the divergent northward flow acting on the large-scale density gradient was found to enhance root-mean-square alongshore density gradients (W20). Here, the cross-shore front occurrence and elevated density gradients were much more likely for stronger northward subtidal flow (Fig. 8a). This suggests that the crossshore fronts, whose ensemble had gravity current like dynamics, is generated by the combined convergent northward flow acting on the large-scale density field.

\section{Summary}

Here, we investigate the kinematics and dynamics of the coastal (within $10 \mathrm{~km}$ from shore and $<30$-m water depth) density fronts, using a high-resolution numerical model of the San Diego Bight (W20). Density fronts are first identified using the Canny edge detection algorithm and then categorized into alongshore and cross-shore-oriented fronts. Statistics of front properties show that, the cross-shore fronts are about $1 / 3$ as numerous as the alongshore fronts. For both front groups, the mean front length reaches $6-8 \mathrm{~km}$, the alongfront averaged surface density gradient varies from 2 to $20 \times 10^{-4} \mathrm{~kg} \mathrm{~m}^{-4}$. Most $(\approx 2 / 3)$ alongshore fronts have lighter water offshore, while $90 \%$ of cross-shore fronts have lighter water to the north. The alongshore front activity is enhanced by onshore surface diurnal flow, indicating onshore propagating internal warm bores. In contrast, the cross-shore front activity is promoted by northward subtidal alongshore flow.

The cross-shore front dynamics are further examined using a subset of the cross-shore fronts that have a negative cross-front density gradient (lighter water to the north). The density and flow field are decomposed into cross-front mean and perturbation components, and then ensemble averaged to generate 
an ensemble cross-shore front. The cross-front mean flow is largely in geostrophic balance in the along- and cross-front directions. The ensemble front extends several kilometers from shore with a distinct linear front axis and convergent perturbation cross-front flow within the upper $5 \mathrm{~m}$. The perturbation alongfront flow within the upper $5 \mathrm{~m}$ is more offshore (onshore) directed on the light (dense) side and weakens onshore. Downwelling occurs on the front dense side, and weaker upwelling occurs on the light side. The ensemble mean front is frontogenetic as the cross-front convergence dominates over the frontolytic vertical advection. Vertical mixing of momentum is weak, indicating that the turbulent thermal wind mechanism is not active. The perturbation alongfront momentum balance is largely geostrophic, while the cross-front balance is between the pressure gradient and the material acceleration, analogous to a gravity current. This contrasts with the cross-front geostrophic and alongfront ageostrophic balances in classic deformation frontognesis, but is consistent with shoreline-bounded semigeostrophic coastal circulation. Given that alongshore nonuniform density and alongshore convergent flows are ubiquitous in coastal waters, shallow cross-shore fronts may also occur at many other locations.

Acknowledgments. This work was supported by the National Science Foundation (OCE-1459389) as part of the CrossSurfzone/Inner-shelf Dye Exchange (CSIDE) experiment. Additional funding is through the Environmental Protection Agency through the North American Development Bank, however it does not necessarily reflect the policies, actions, or positions of the U.S. EPA or NADB. This work used the Extreme Science and Engineering Discovery Environment (XSEDE), which is supported by National Science Foundation (ACI-1548562). The numerical simulations were performed on the comet cluster at the San Diego Supercomputer Center through XSEDE allocation TG-OCE180013. NOAA provided the NAM atmospheric forcing fields and the bathymetry. SIO Coastal Data Information Program provided wave forcing. Ganesh Gopalakrishnan and Bruce Cornuelle provided CASE model solutions which are available online (http://ecco.ucsd.edu/ case.html). We also appreciate extra support from the Tijuana River National Estuarine Research Reserve and the Southern California Coastal Ocean Observing System. Geno Pawlak, Derek Grimes, Angelica Rodriguez, and Nirnimesh Kumar provided useful feedback on this work. We thank two anonymous reviewers for helpful comments that improved this manuscript.

\section{REFERENCES}

Akan, Ç., J. C. McWilliams, S. Moghimi, and H. T. Özkan-Haller, 2018: Frontal dynamics at the edge of the Columbia River plume. Ocean Modell., 122, 1-12, https://doi.org/10.1016/ j.ocemod.2017.12.001.

Allen, J. S., 1980: Models of wind-driven currents on the continental shelf. Annu. Rev. Fluid Mech., 12, 389-433, https:// doi.org/10.1146/annurev.fl.12.010180.002133.

Austin, J. A., and J. A. Barth, 2002: Variation in the position of the upwelling front on the Oregon shelf. J. Geophys. Res., 107, 3180, https://doi.org/10.1029/2001JC000858.
—_ and S. J. Lentz, 2002: The inner shelf response to winddriven upwelling and downwelling. J. Phys. Oceanogr., 32, 2171-2193, https://doi.org/10.1175/1520-0485(2002)032<2171: TISRTW $>2.0 . \mathrm{CO} ; 2$.

Banas, N., P. MacCready, and B. Hickey, 2009: The columbia river plume as cross-shelf exporter and along-coast barrier. Cont. Shelf Res., 29, 292-301, https://doi.org/10.1016/j.csr.2008.03.011.

Barkan, R., M. J. Molemaker, K. Srinivasan, J. C. McWilliams, and E. A. D. Asaro, 2019: The role of horizontal divergence in submesoscale frontogenesis. J. Phys. Oceanogr., 49, 15931618, https://doi.org/10.1175/JPO-D-18-0162.1.

Benjamin, T. B., 1968: Gravity currents and related phenomena. J. Fluid Mech., 31, 209-248, https://doi.org/10.1017/S0022112068000133.

Bleck, R., R. Onken, and J. Woods, 1988: A two-dimensional model of mesoscale frontogenesis in the ocean. Quart. J. Roy. Meteor. Soc., 114, 347-371, https://doi.org/10.1002/qj.49711448005.

Booij, N., R. C. Ris, and L. H. Holthuijsen, 1999: A thirdgeneration wave model for coastal regions: 1 . Model description and validation. J. Geophys. Res., 104, 7649-7666, https:// doi.org/10.1029/98JC02622.

Brink, K., 1987: Upwelling fronts: Implications and unknowns. S. Afr. J. Mar. Sci., 5, 3-9, https://doi.org/10.2989/025776187784522315.

Callies, J., R. Ferrari, J. M. Klymak, and J. Gula, 2015: Seasonality in submesoscale turbulence. Nat. Commun., 6, 6862, https:// doi.org/10.1038/ncomms7862.

Canny, J., 1986: A computational approach to edge detection. IEEE Trans. Pattern Anal. Mach. Intell., PAMI-8, 679-698, https://doi.org/10.1109/TPAMI.1986.4767851.

Castelao, R. M., T. P. Mavor, J. A. Barth, and L. C. Breaker, 2006: Sea surface temperature fronts in the California Current System from geostationary satellite observations. J. Geophys. Res., 111, C09026, https://doi.org/10.1029/2006JC003541.

Chant, R., 2011: Interactions between estuaries and coasts: River plumes their formation, transport, and dispersal. Treatise on Estuarine and Coastal Science, E. Wolanski and D. McLusky, Eds., Academic Press, 213-235, https://doi.org/10.1016/B9780-12-374711-2.00209-6.

Colosi, J. A., N. Kumar, S. H. Suanda, T. M. Freismuth, and J. H. MacMahan, 2018: Statistics of internal tide bores and internal solitary waves observed on the inner continental shelf off Point Sal, California. J. Phys. Oceanogr., 48, 123-143, https:// doi.org/10.1175/JPO-D-17-0045.1.

Connolly, T. P., and A. R. Kirincich, 2019: High-resolution observations of subsurface fronts and alongshore bottom temperature variability over the inner shelf. J. Geophys. Res. Oceans, 124, 593-614, https://doi.org/10.1029/2018JC014454.

Dauhajre, D. P., J. C. McWilliams, and Y. Uchiyama, 2017: Submesoscale coherent structures on the continental shelf. J. Phys. Oceanogr., 47, 2949-2976, https://doi.org/10.1175/ JPO-D-16-0270.1.

—_ — - and L. Renault, 2019: Nearshore Lagrangian connectivity: Submesoscale influence and resolution sensitivity. J. Geophys. Res. Oceans, 124, 5180-5204, https:// doi.org/10.1029/2019JC014943.

Dewey, R. K., and J. N. Moum, 1990: Enhancement of fronts by vertical mixing. J. Geophys. Res., 95, 9433-9445, https:// doi.org/10.1029/JC095iC06p09433.

Dinniman, M. S., and M. M. Rienecker, 1999: Frontogenesis in the North Pacific oceanic frontal zones-A numerical simulation. J. Phys. Oceanogr., 29, 537-559, https://doi.org/10.1175/15200485(1999)029<0537:FITNPO>2.0.CO;2.

Dong, C., E. Y. Idica, and J. C. McWilliams, 2009: Circulation and multiple-scale variability in the Southern California Bight. 
Prog. Oceanogr., 82, 168-190, https://doi.org/10.1016/ j.pocean.2009.07.005.

Feddersen, F., M. Olabarrieta, R. T. Guza, D. Winters, B. Raubenheimer, and S. Elgar, 2016: Observations and modeling of a tidal inlet dye tracer plume. J. Geophys. Res. Oceans, 121, 7819-7844, https://doi.org/10.1002/2016JC011922.

Franks, P. J., 1992: Phytoplankton blooms at fronts: Patterns, scales, and physical forcing mechanisms. Rev. Aquat. Sci., 6, 121-137.

Garrett, C. J. R., and J. Loder, 1981: Dynamical aspects of shallow sea fronts. Philos. Trans. Roy. Soc. London, 302A, 563-581, https://doi.org/10.1098/rsta.1981.0183.

Geyer, W. R., and D. K. Ralston, 2015: Estuarine frontogenesis. J. Phys. Oceanogr., 45, 546-561, https://doi.org/10.1175/JPOD-14-0082.1.

Grimes, D. J., F. Feddersen, S. N. Giddings, and G. Pawlak, 2020: Cross-shore deformation of a surfzone-released dye plume by an internal tide on the inner shelf. J. Phys. Oceanogr., 50, 3554, https://doi.org/10.1175/JPO-D-19-0046.1.

Gula, J., M. J. Molemaker, and J. C. McWilliams, 2014: Submesoscale cold filaments in the Gulf Stream. J. Phys. Oceanogr., 44, 26172643, https://doi.org/10.1175/JPO-D-14-0029.1.

Hally-Rosendahl, K., F. Feddersen, D. B. Clark, and R. Guza, 2015: Surfzone to inner-shelf exchange estimated from dye tracer balances. J. Geophys. Res. Oceans, 120, 6289-6308, https://doi.org/10.1002/2015JC010844.

Horner-Devine, A. R., R. D. Hetland, and D. G. MacDonald, 2015: Mixing and transport in coastal river plumes. Annu. Rev. Fluid Mech., 47, 569-594, https://doi.org/10.1146/annurev-fluid010313-141408.

Hoskins, B. J., 1982: The mathematical theory of frontogenesis. Annu. Rev. Fluid Mech., 14, 131-151, https://doi.org/10.1146/ annurev.fl.14.010182.001023.

—, and F. P. Bretherton, 1972: Atmospheric frontogenesis models: Mathematical formulation and solution. J. Atmos. Sci., 29, 11-37, https://doi.org/10.1175/1520-0469(1972)029<0011: AFMMFA $>2.0 . \mathrm{CO} ; 2$.

—, I. Draghici, and H. Davies, 1978: A new look at the $\omega$-equation. Quart. J. Roy. Meteor. Soc., 104, 31-38, https:// doi.org/10.1002/qj.49710443903.

Huyer, A., 1983: Coastal upwelling in the California Current System. Prog. Oceanogr., 12, 259-284, https://doi.org/10.1016/ 0079-6611(83)90010-1.

Huzzey, L. M., and J. M. Brubaker, 1988: The formation of longitudinal fronts in a coastal plain estuary. J. Geophys. Res., 93, 1329-1334, https://doi.org/10.1029/JC093iC02p01329.

Johnson, E. S., 1996: A convergent instability wave front in the central tropical Pacific. Deep-Sea Res. II, 43, 753-778, https:// doi.org/10.1016/0967-0645(96)00034-3.

Johnson, L., C. M. Lee, E. A. D. Asaro, L. Thomas, and A. Shcherbina, 2020: Restratification at a California Current upwelling front. Part I: Observations. J. Phys. Oceanogr., 50, 1455-1472, https://doi.org/10.1175/JPO-D-19-0203.1.

Jones, C. T., T. D. Sikora, P. W. Vachon, and J. Wolfe, 2012: Toward automated identification of sea surface temperature front signatures in Radarsat-2 images. J. Atmos. Oceanic Technol., 29, 89-102, https://doi.org/10.1175/JTECH-D-1100088.1.

Kahru, M., E. Di Lorenzo, M. Manzano-Sarabia, and B. G. Mitchell, 2012: Spatial and temporal statistics of sea surface temperature and chlorophyll fronts in the California Current. J. Plankton Res., 34, 749-760, https://doi.org/10.1093/plankt/ fbs010.
Kantha, L. H., and C. A. Clayson, 1994: An improved mixed layer model for geophysical applications. J. Geophys. Res., 99, 25 235-25 266, https://doi.org/10.1029/94JC02257.

Kumar, N., G. Voulgaris, J. C. Warner, and M. Olabarrieta, 2012: Implementation of the vortex force formalism in the Coupled Ocean-Atmosphere-Wave-Sediment Transport (COAWST) modeling system for inner shelf and surf zone applications. Ocean Modell., 47, 65-95, https://doi.org/ 10.1016/j.ocemod.2012.01.003.

_, F. Feddersen, Y. Uchiyama, J. McWilliams, and W. O. Reilly, 2015: Midshelf to surfzone coupled ROMS-SWAN model data comparison of waves, currents, and temperature: Diagnosis of subtidal forcings and response. J. Phys. Oceanogr., 45, 14641490, https://doi.org/10.1175/JPO-D-14-0151.1.

— S. H. Suanda, J. A. Colosi, K. Haas, E. Di Lorenzo, A. J. Miller, and C. A. Edwards, 2019: Coastal semidiurnal internal tidal incoherence in the Santa Maria basin, California: Observations and model simulations. J. Geophys. Res. Oceans, 124, 5158-5179, https://doi.org/10.1029/2018JC014891.

Lentz, S. J., R. T. Guza, S. Elgar, F. Feddersen, and T. H. C. Herbers, 1999: Momentum balances on the North Carolina inner shelf. J. Geophys. Res., 104, 18 205-18226, https:// doi.org/10.1029/1999JC900101.

_, S. Elgar, and R. Guza, 2003: Observations of the flow field near the nose of a buoyant coastal current. J. Phys. Oceanogr., 33, 933-943, https://doi.org/10.1175/1520-0485(2003)33<933: OOTFFN $>2.0 . \mathrm{CO} ; 2$.

Lévy, M., P. J. Franks, and K. S. Smith, 2018: The role of submesoscale currents in structuring marine ecosystems. Nat. Commun., 9, 4758, https://doi.org/10.1038/s41467-018-07059-3.

Mahadevan, A., 2016: The impact of submesoscale physics on primary productivity of plankton. Annu. Rev. Mar. Sci., 8, 161184, https://doi.org/10.1146/annurev-marine-010814-015912.

Mauzole, Y., H. Torres, and L.-L. Fu, 2020: Patterns and dynamics of SST fronts in the California Current System. J. Geophys. Res. Oceans, 125, e2019JC015499, https://doi.org/10.1029/ 2019JC015499.

McSweeney, J. M., and Coauthors, 2020: Observations of shoaling nonlinear internal bores across the central California inner shelf. J. Phys. Oceanogr., 50, 111-132, https://doi.org/10.1175/ JPO-D-19-0125.1.

McWilliams, J. C., 2016: Submesoscale currents in the ocean. Proc. Roy. Soc., 472A, 20160117, https://doi.org/10.1098/rspa.2016.0117.

_ 2017: Submesoscale surface fronts and filaments: Secondary circulation, buoyancy flux, and frontogenesis. J. Fluid Mech., 823, 391-432, https://doi.org/10.1017/jfm.2017.294.

_ J. Jula, M. J. Molemaker, L. Renault, and A. F. Shchepetkin, 2015: Filament frontogenesis by boundary layer turbulence. J. Phys. Oceanogr., 45, 1988-2005, https://doi.org/10.1175/ JPO-D-14-0211.1.

Moum, J. N., J. M. Klymak, J. D. Nash, A. Perlin, and W. D. Smyth, 2007: Energy transport by nonlinear internal waves. J. Phys. Oceanogr., 37, 1968-1988, https://doi.org/10.1175/JPO3094.1.

Nagai, T., N. Gruber, H. Frenzel, Z. Lachkar, J. C. McWilliams, and G.-K. Plattner, 2015: Dominant role of eddies and filaments in the offshore transport of carbon and nutrients in the California Current System. J. Geophys. Res. Oceans, 120, 5318-5341, https://doi.org/10.1002/2015JC010889.

O'Donnell, J., 2010: The dynamics of estuary plumes and fronts. Contemporary Issues in Estuarine Physics, Cambridge University Press, 186-246, https://doi.org/10.1017/CBO9780511676567.009.

Ohlmann, J., M. Molemaker, B. Baschek, B. Holt, G. Marmorino, and G. Smith, 2017: Drifter observations of submesoscale flow 
kinematics in the coastal ocean. Geophys. Res. Lett., 44, 330337, https://doi.org/10.1002/2016GL071537.

Palacios, D. M., S. J. Bograd, R. Mendelssohn, and F. B. Schwing, 2004: Long-term and seasonal trends in stratification in the California Current, 1950-1993. J. Geophys. Res., 109, C10016, https://doi.org/10.1029/2004JC002380.

Pallàs-Sanz, E., T. Johnston, and D. Rudnick, 2010: Frontal dynamics in a California Current System shallow front: 1 . Frontal processes and tracer structure. J. Geophys. Res., 115, C12067, https://doi.org/10.1029/2009JC006032.

Pham, H. T., and S. Sarkar, 2018: Ageostrophic secondary circulation at a submesoscale front and the formation of gravity currents. J. Phys. Oceanogr., 48, 2507-2529, https://doi.org/ 10.1175/JPO-D-17-0271.1.

Rao, S., J. Pringle, and J. Austin, 2011: Upwelling relaxation and estuarine plumes. J. Geophys. Res., 116, C09023, https:// doi.org/10.1029/2010JC006739.

Romero, L., Y. Uchiyama, J. C. Ohlmann, J. C. McWilliams, and D. A. Siegel, 2013: Simulations of nearshore particle-pair dispersion in Southern California. J. Phys. Oceanogr., 43, 1862-1879, https://doi.org/10.1175/JPO-D-13-011.1.

—, D. A. Siegel, J. C. McWilliams, Y. Uchiyama, and C. Jones, 2016: Characterizing storm water dispersion and dilution from small coastal streams. J. Geophys. Res. Oceans, 121, 39263943, https://doi.org/10.1002/2015JC011323.

Shchepetkin, A. F., and J. C. McWilliams, 2005: The Regional Oceanic Modeling System (ROMS): A split-explicit, free-surface, topography-following-coordinate oceanic model. Ocean Modell., 9, 347-404, https://doi.org/10.1016/j.ocemod.2004.08.002.

Simpson, J., C. Allen, and N. Morris, 1978: Fronts on the continental shelf. J. Geophys. Res., 83, 4607-4614, https://doi.org/ 10.1029/JC083iC09p04607.

Sinnett, G., F. Feddersen, A. J. Lucas, G. Pawlak, and E. Terrill, 2018: Observations of nonlinear internal wave run-up to the surfzone. J. Phys. Oceanogr., 48, 531-554, https://doi.org/ 10.1175/JPO-D-17-0210.1.

Spall, M. A., 1995: Frontogenesis, subduction, and cross-front exchange at upper ocean fronts. J. Geophys. Res., 100, 25432557, https://doi.org/10.1029/94JC02860.
Suanda, S. H., F. Feddersen, and N. Kumar, 2017: The effect of barotropic and baroclinic tides on coastal stratification and mixing. J. Geophys. Res. Oceans, 122, 10156-10173, https:// doi.org/10.1002/2017JC013379.

Sutherland, B. R., 2010: Internal Gravity Waves. Cambridge University Press, 377 pp., https://doi.org/10.1017/CBO9780511780318.

Thomas, L. N., A. Tandon, and A. Mahadevan, 2008: Submesoscale processes and dynamics. Ocean Modeling in an Eddying Regime, Geophys. Monogr., Vol. 177, Amer. Geophys. Union, 17-38, https://doi.org/10.1029/177GM04.

Thompson, L., 2000: Ekman layers and two-dimensional frontogenesis in the upper ocean. J. Geophys. Res., 105, 6437-6451, https://doi.org/10.1029/1999JC900336.

Towns, J., and Coauthors, 2014: Xsede: Accelerating scientific discovery. Comput. Sci. Eng., 16, 62-74, https://doi.org/ 10.1109/MCSE.2014.80.

Umlauf, L., and H. Burchard, 2003: A generic length-scale equation for geophysical turbulence models. J. Mar. Res., 61, 235265, https://doi.org/10.1357/002224003322005087.

Warner, J. C., B. Armstrong, R. He, and J. B. Zambon, 2010: Development of a Coupled Ocean-Atmosphere-Wave-Sediment Transport (COAWST) modeling system. Ocean Modell., 35, 230244, https://doi.org/10.1016/j.ocemod.2010.07.010.

Warner, S. J., R. M. Holmes, E. H. M. Hawkins, M. S. HoeckerMartínez, A. C. Savage, and J. N. Moum, 2018: Buoyant gravity currents released from tropical instability waves. J. Phys. Oceanogr., 48, 361-382, https://doi.org/10.1175/JPO-D-17-0144.1.

Wenegrat, J. O., and M. J. McPhaden, 2016: Wind, waves, and fronts: Frictional effects in a generalized Ekman model. J. Phys. Oceanogr., 46, 371-394, https://doi.org/10.1175/JPOD-15-0162.1.

Winant, C. D., and C. E. Dorman, 1997: Seasonal patterns of surface wind stress and heat flux over the Southern California Bight. J. Geophys. Res., 102, 5641-5653, https://doi.org/ 10.1029/96JC02801.

Wu, X., F. Feddersen, S. N. Giddings, N. Kumar, and G. Gopalakrishnan, 2020: Mechanisms of mid- to outer-shelf transport of shoreline-released tracers. J. Phys. Oceanogr., 50, 1813-1837, https://doi.org/10.1175/JPO-D-19-0225.1. 